\title{
Optimizing prophylactic treatment of migraine: Subtypes and patient matching
}

Michel Dib

Fédération du système nerveux central, Hôpital de la Salpêtrière, Assistance Publique- Hôpitaux de Paris, France
Correspondence: Dr Michel Dib Fédération du système nerveux central, Hôpital de la Salpêtrière, Assistance Publique-Hôpitaux de Paris, France

$\mathrm{Tel}+33$ । 45709 9 90

$\mathrm{Fax}+33$ । 45709 I 50

Email dib.michel@wanadoo.fr

\begin{abstract}
Advances in our understanding of the pathophysiology of migraine have resulted in important breakthroughs in treatment. For example, understanding of the role of serotonin in the cerebrovascular circulation has led to the development of triptans for the acute relief of migraine headaches, and the identification of cortical spreading depression as an early central event associated wih migraine has brought renewed interest in antiepileptic drugs for migraine prophylaxis. However, migraine still remains inadequately treated. Indeed, it is apparent that migraine is not a single disease but rather a syndrome that can manifest itself in a variety of pathological conditions. The consequences of this may be that treatment needs to be matched to particular patients. Clinical research needs to be devoted to identifying which sort of patients benefit best from which treatments, particularly in the field of prophylaxis. We propose four patterns of precipitating factors (adrenergic, serotoninergic, menstrual, and muscular) which may be used to structure migraine prophylaxis. Finally, little is known about long-term outcome in treated migraine. It is possible that appropriate early prophylaxis may modify the long-term course of the disease and avoid late complications.
\end{abstract}

Keywords: migraine, diagnosis, treatment, prophylaxis, subtypes

Migraine headaches are the most frequent type of incapacitating headache and one of the most common reasons for consultation in neurology. However, these headaches have historically been poorly understood in terms of natural history, pathophysiology and prognosis. This unsatisfactory state of affairs had important consequences for the diagnosis and treatment of migraine, which have been frequently inadequate. Indeed, the first rational classification of headache semiology, providing an unambiguous definition of migraine was established relatively recently by the International Headache Society in 1988 (HCCIHS 1988) (revised in 2004 [HCCIHS 2004]). This provides a framework for the standardized diagnosis of migraine.

For this reason, there is little available data on long-term disease course from natural history cohorts which have used this diagnosis classification. In particular, although headache relief treatments, often with over-the-counter analgesic drugs, are widely used, the long-term management of migraine, involving prophylactic treatments and the implementation of strategies to prevent headache evolution to more severe disease and to promote remission, has been explored relatively little. This situation has changed somewhat over recent years with the introduction of standardized guidelines for the diagnosis and treatment of migraine headaches. Moreover, the introduction of triptans as a specific treatment for relief of migraine headaches has stimulated much research into the biology of migraine, leading to a better understanding of its pathophysiology. This articles reviews recent developments in our understanding of migraine and their consequences for improved management of migraine as a chronic disease. 


\section{Natural history of migraine}

Migraine headache generally presents for the first time during adolescence, with a lower mean age of onset in males than in females (Ulrich et al 1999). However, migraine does occur in younger children (Abu-Arefeh and Russell 1994; Annequin et al 2000) and may be under-diagnosed due to difficulties in assessing accurately symptomatology in this population.

There have been few longitudinal studies investigating long-term outcome of migraine headache. However, given that the prevalence of migraine decreases with age, it can be expected that, in many cases, these headaches resolve spontaneously. Two recent studies have evaluated long-term outcome in larger populations whose original migraine diagnosis was established using the IHS criteria. The first study followed up 549 of 740 subjects originally diagnosed with episodic headaches in 1989 (Lyngberg et al 2005). Twelve years after the original diagnosis, $42 \%$ of subjects were in remission, 38\% had less frequent headaches and $20 \%$ had more frequent headaches. Poor outcome was associated with high migraine frequency at baseline and age at onset younger than 20 years. For tension-type headache, remission was observed in $45 \%$ of subjects and transformation into a chronic tension-type headache was reported in $16 \%$. The second study evaluated 1250 of 2051 subjects originally identified in 2003, of whom 398 fulfilled diagnostic criteria for migraine (Nachit-Ouinekh et al 2005). Ten years later, $37 \%$ stilled fulfilled these criteria, whereas $36 \%$ now fulfilled diagnostic criteria for migrainous disorder and $18 \%$ for other episodic headache types, the remainder being in complete remission. Remission or evolution to a less severe headache was more frequent in men and in older subjects.

\section{Chronic headache presentations}

These longitudinal studies identify a minority of subjects whose condition deteriorates with time, notably with an increased frequency of headaches. This corresponds to the notion of transformed migraine (Mathew et al 1982) or chronic daily headache. Many of these headaches may be iatrogenic and high levels of analgesic drug use have been described in up to three-quarters of cases (Mathew 1997) and are associated with a risk of transformation (Zwart et al 2003; Dowson et al 2005). Although analgesic drugs have been implicated most frequently in the development of chronic daily headaches, recent studies suggest that use of specific acute migraine treatments (triptans) may also lead to transformation of migraine (Limmroth et al 2002). High caffeine use has also been described as a risk factor for transformation (Scher et al 2004). Psychiatric comorbidity, notable depression, may also be associated with an increased risk of transformation (Mathew 1997; Wang et al 2000).

In addition, tension-type headaches may also evolve into a chronic form. Chronic tension-type headaches, as defined in the IHS classification, occur with a frequency of over 180 days per year and are distinguished from transformed migraine (or chronic daily headache with migrainous features) by their characteristic symptom presentation (steady rather than pulsatile pain, bilateral rather than unilateral, etc). Some characteristic features of migraine, such as nausea, are less prevalent in subjects with chronic daily headache than in those with classical migraine headache (Solomon et al 1992; Mathew 1993; Lanteri-Minet et al 2003). The overall prevalence of chronic daily headache in the general population is around 4\% (Wang et al 2000; Scher et al 1998; Castillo et al 1999; Lanteri-Minet et al 2003), with most studies reporting chronic tension-type headache to be more frequent than transformed migraine. Individuals presenting with these headache types represent a large segment of the population consulting specialist headache centres. Chronic daily headaches often remit spontaneously, and a one-year remission rate of $14 \%$ has been estimated from a general population sample (Scher et al 2003). Factors associated with a poor prognosis of chronic daily headache include older age, long duration of chronic headaches and medication overuse (Wang et al 2000; Lu et al 2001).

\section{Consequences for treatment}

The long-term outcome of migraine can thus be variable (Figure 1) and it is an important objective of therapy to ensure a favorable outcome (remission). This raises a number of important questions. Classical migraine can be managed effectively with acute or prophylactic treatments (see below) although analgesic drugs should be avoided as headache relief medication in order to reduce the risk of transformation to a chronic headache type. Certain of these drugs may be acquired over the counter and used as selfmedication, and it is important to identify and discourage such habits in patients consulting for migraine headache. In patients whose headaches have already transformed into a chronic presentation, medication withdrawal can in many cases be sufficient to promote remission (Linton-Dahlof et al 2000; Kavuk et al 2004).

Migrainous disorder can be considered as a 'mild' form of classical migraine and clinical experience suggests that these headaches respond to the same relief medications as the latter disorder, although this has not been evaluated specifically in randomized clinical trials. A methodical evaluation 


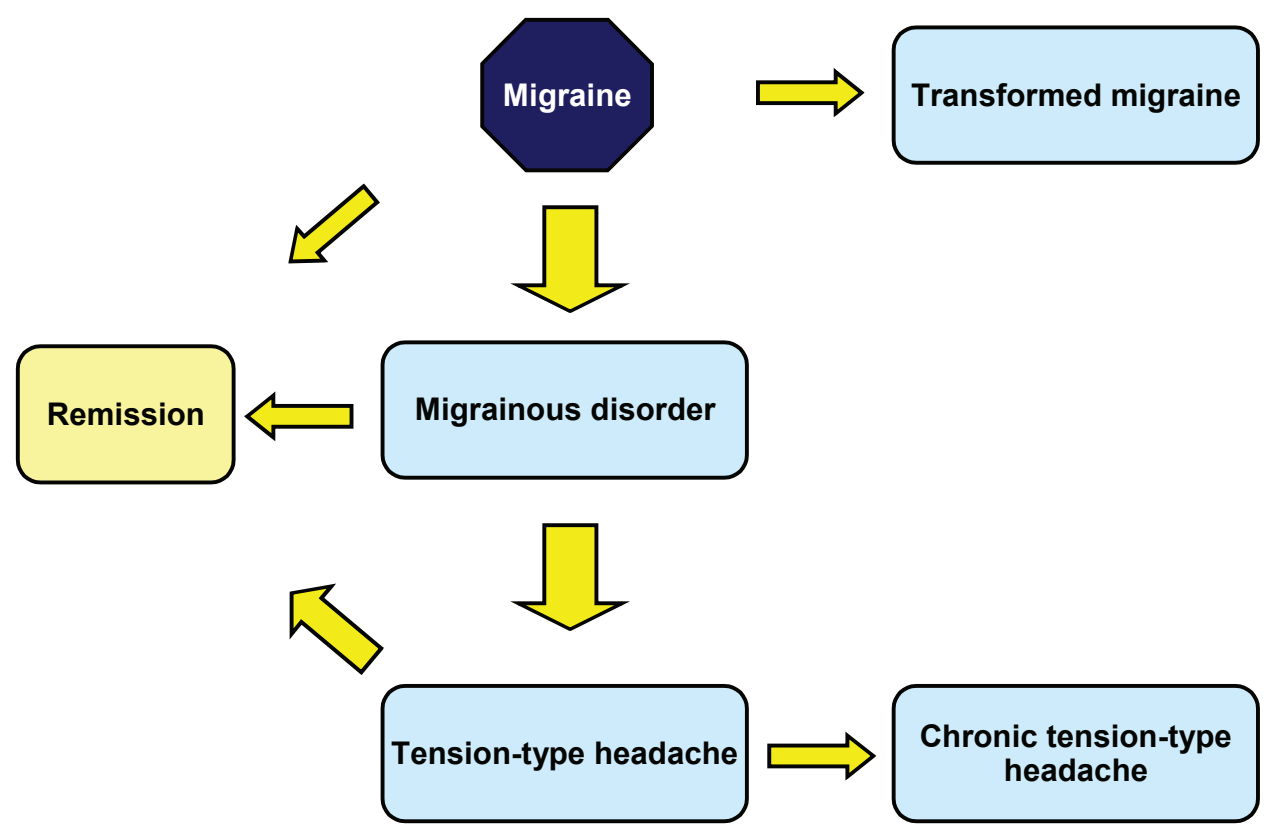

Figure I Potential long-term course of migraine headaches.

of symptoms is recommended in order to distinguish these headaches from tension-type headaches and to treat them appropriately.

It is not clear whether tension-type headache that is secondary to migraine headache ('burnt-out' migraine) differs from primary tension-type headaches in their physiopathology and in their response to treatments. For example, two randomized clinical trials have shown sumatriptan to be inefficacious in primary tension-type headaches (Brennum et al 1996; Lipton et al 2000a) but their utility in secondary tension-type headaches evolving from migraine is unknown.

Another important unanswered question relates to whether early and intensive drug treatment of migraine headaches changes the probability of a favorable outcome. In another paroxystic neurological disorder, epilepsy, this is an established therapeutic principle, and merits investigation in long-term follow-up studies of patients presenting with and treated for migraine headaches.

\section{Migraine as a syndrome}

It is increasingly apparent that migraine is best understood as a syndrome expressed in several different subtypes of underlying disease. These various subtypes differ in their symptom presentation and are also likely to respond better to certain treatments than to others. A major challenge is to identify the most appropriate treatments for each subtype of migraine.
Familial hemiplegic migraine is probably only the first form of familial migraine whose genetic basis has been elucidated. This form of migraine headache can be considered a channelopathy in which symptoms arise due to a change in the gating kinetics of $\mathrm{P} / \mathrm{Q}$ type calcium channels brought about by the mutations (Kraus et al 1998, 2000). The consequence of this may be an impairment of local GABAergic inhibitory circuits (Cao and Tsien 2005). It may also be possible to define subtypes of migraine headache based on differences in precipitating factors. First of all, stressinduced headache, mediated by an adrenergic mechanism may be a specific migraine subtype. Stress is the most frequently cited precipitating factor and related to a particular pattern of physiological activation, namely activation of the hypothalamo-pituitary-adenocortical axis and increased sympathetic tone. This may lead to increased vasoconstrictor tone in the cerebral vasculature and thus sensitize individuals to migraine headache.

Mood and sleep disturbances are also common precipitating factors for migraine and these are associated with the central serotonergic system. Another group of precipitating factors relates to sensory stimuli such as particular smells (tobacco or perfume) or foodstuffs (cheese, alcohol, chocolate) and these may also implicate serotonergic mechanisms.

Menstrual migraine provides an example of a form of migraine with a specific precipitating factor, pathogenesis 
and treatment. Around half of women with migraine report menstruation to be a precipitating factor (Henry et al 2002; Zivadinov et al 2003) and the frequency of migraine attacks varies over the reproductive cycle (Granella et al 1993). A recent large prospective survey in a population of 153 women with migraine (MacGregor 2004) identified a relative risk of migraine headache of 1.7 in the two days preceding menstruation and of 2.3 in the first three days of menstruation compared to all other times of the cycle. Menstrual migraine attacks have been reported to be of longer duration and to be more incapacitating than non-menstrual migraine (Couturier et al 2003; Granella et al 2004).

In women with 'pure' menstrual migraine (ie, those who only have headache attacks at the onset of menstruation and not at other times of the cycle), the onset of headache has been associated with rapidly falling plasma concentrations of estrogen (Somerville 1972). Indeed, women with menstrual migraine show larger swings in estrogen levels across the menstrual cycle than did women without menstrual migraine (Epstein et al 1975). Estrogen challenge experiments have shown that migraine can be precipitated following artificial elevations of plasma estrogen levels both in women with active menstrual migraine (Somerville 1975) and in postmenopausal women with antecedents of menstrual migraine (Lichten et al 1996; Facchinetti et al 2002). This hypothesis is also supported by the observation that women taking oral contraceptives often experience headache during the estrogen-free week and by reports of emergent migraine in women interrupting hormone replacement therapy (MacGregor 2004). Exactly how fluctuations in estrogen levels trigger headache is, on the other hand, far from clear. Estrogens have a number of effects on the nervous system involving both genomic actions and direct effects on neuronal excitability (McEwen 2001). These latter may sensitize the nervous system to cortical spreading depression or modify gating of nociceptive stimuli in the trigeminal nucleus. Studies in experimental animals have provided evidence for a change in the sensitivity of the $\mathrm{GABA}_{\mathrm{A}}$ receptor over the course of the estrous cycle (Carey et al 1992; Diaz-Veliz et al 2000). It should also be pointed out that estrogens have direct effects on the cerebral vasculature (Littleton-Kearney et al 2000) which may also contribute to the occurrence of migraine headaches. Menstrual migraine can be treated not only with headache medication active in all types of migraine, but also with specific hormonal treatments aimed at attenuating estrogen withdrawal (Loder et al 2005). These are described in more detail below.

Finally, certain otherwise typical pulsatile migraine headaches may share features typical of tension-type headaches such as a sensation of muscular pressure or tension, and represent a mixed headache type. These headaches generally localise to the posterior occipital cortex and have a high probability of transformation into a chronic headache type. Whether such headaches are a transition stage in the deteriorating course of certain classical migraine headaches or represent a subtype of migraine with a distinct aetiopathology is unclear, but they are frequently associated with muscular diseases like fibromyalgia.

A proposed classification of migraine headaches based on triggering factors is presented in Figure 2. The case of menstrual migraine, where a specific prophylaxis can be proposed may illustrate a general principle, and it will be interesting to see whether other prophylactic treatments may be particularly effective in migraineurs with particular patterns of precipitating factors. For example, beta-blockers such as propranolol, or alpha-blockers such as indoramine may be particularly effective in Type A migraine (as defined in Figure 2) whereas antiserotonergic drugs such as methysergide, dihydroergotamine or pizotofen may be more effective in Type B migraine. Hormone therapy is clearly useful in Type C (see below), and muscle relaxant and antidepressant drugs like amitriptyline seem effective in Type D, associated with other prophylactic migraine treatments where necessary. Adequately designed randomized clinical trials will be required to test these hypotheses. Of course, in medical practice patients presenting features typical of more than one headache type are frequently encountered. In these cases, the optimal therapeutic strategy may require association of two or three of these drugs.

\section{Acute treatment of migraine headaches}

Four classes of drug are used as acute treatments for the relief of headache. Nonsteroidal antiinflammatory drugs (NSAIDs) and analgesics represent non-specific headache relief medications and the triptans and ergot alkaloids migraine-specific treatments. NSAIDs are generally preferred to analgesics as non-specific treatments, since the latter drugs have a high perceived risk of leading to the development of chronic medication-overuse headaches (Zwart et al 2003). However, all acute treatments may to a greater or lesser extent lead to medication overuse headache and prophylactic treatments should be used in patients with frequent headaches to reduce headache frequency and thus recourse to acute medication. Triptans have come to supersede ergot alkaloids as specific headache relief treatments in many countries as they are perceived to have superior tolerability and efficacy. 

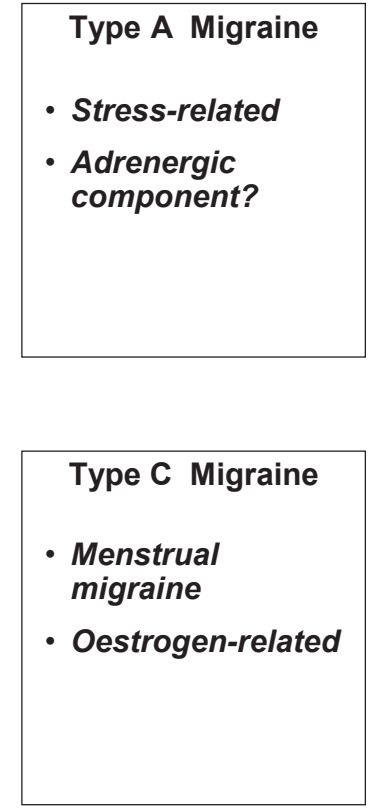

Figure 2 A classification of migraine headaches based on triggering factors.

Various treatment strategies for headache relief have been proposed that combine these drug classes in which patients initially take a non-specific treatment and then add a triptan, first-line/second-line strategies in which patients are initially prescribed an NSAID and then switched to a triptan in case of non-response, and stratified care, in which NSAIDs or triptans are differentially prescribed according to headache severity.

Non-steroidal anti-inflammatory drugs (NSAIDs) are widely used for acute headache relief both as prescription and over-the-counter medication (Lucas et al 2005). Numerous clinical trials of varying quality have been performed with these agents since the 1960's.

Placebo-controlled trials have shown aspirin to be effective in the relief of migraine headache, either used alone (Boureau et al 1994; Lange et al 2000; MacGregor et al 2002; Lipton et al 2005b), in combination with metoclopramide (Chabriat et al 1994; Tfelt-Hansen et al 1995; Henry et al $1995)$ or in combination with paracetamol and caffeine (Lipton et al 1998). Data from placebo-controlled trials suggests efficacy for ibuprofen (Kloster et al 1992; Nebe et al 1995; Sandrini et al 1998; Kellstein et al 2000; Codispoti et al 2001), including two studies in children (Hamalainen et al 1997; Lewis et al 2002). Diclofenac has proved superior to placebo in several trials (Massiou et al 1991; Dahlof and Bjorkman 1993; The Diclofenac-K/Sumatriptan Migraine Study Group 1999; Peroutka et al 2004). An important advantage of diclofenac appears to be its rapidity of action. An intramuscular injectable form is also available and been
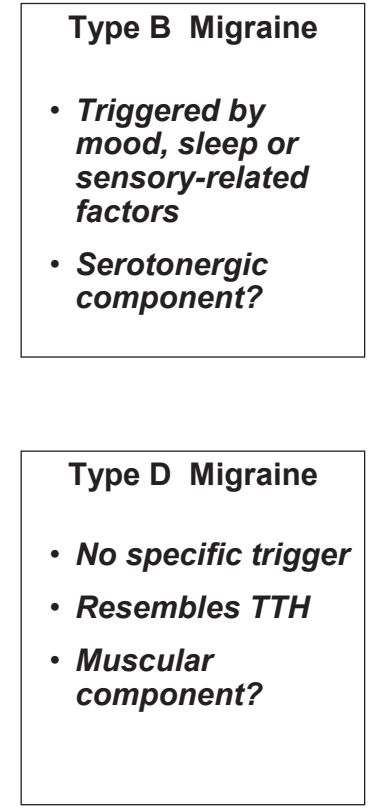

shown to provide rapid headache relief (Karachalios et al 1992; Bigal et al 2002). Ketoprofen has been compared to placebo in a larger study using a standard oral formulation (Dib et al 2002). This study demonstrated superior efficacy for ketoprofen.

Comparative trials with triptans have been performed for oral aspirin compared to oral sumatriptan (Diener et al 2004a), oral aspirin and metoclopramide compared to oral sumatriptan (The Oral Sumatriptan and Aspirin plus Metoclopramide Comparative Study Group 1992; Tfelt-Hansen et al 1995), intravenous aspirin compared to subcutaneous sumatriptan (Diener 1999), oral aspirin and metoclopramide compared to oral zolmitriptan (Geraud et al 2002), oral ibuprofen compared to oral sumatriptan (Diener et al 2004a), oral diclofenac versus oral sumatriptan (The Diclofenac-K/Sumatriptan Migraine Study Group 1999), oral naproxen versus oral naratriptan (Stronks et al 2003), oral tolfenamic acid versus oral sumatriptan (Myllyla et al 1998) and oral ketoprofen versus oral zolmitriptan (Dib et al 2002). With the exception of the asprin/zolmitriptan and noproxen/naratriptan studies, all these trials showed comparable efficacy for the NSAID and the triptan in most, if not all, endpoints. Figure 3 presents data on headache relief at two hours from the ketoprofen/zolmitriptan study. Given the comparable efficacy of NSAIDs to triptans and the considerably lower cost of the latter, many treatment guidelines suggest the use of an NSAID as first-line treatment for migraine headache. 


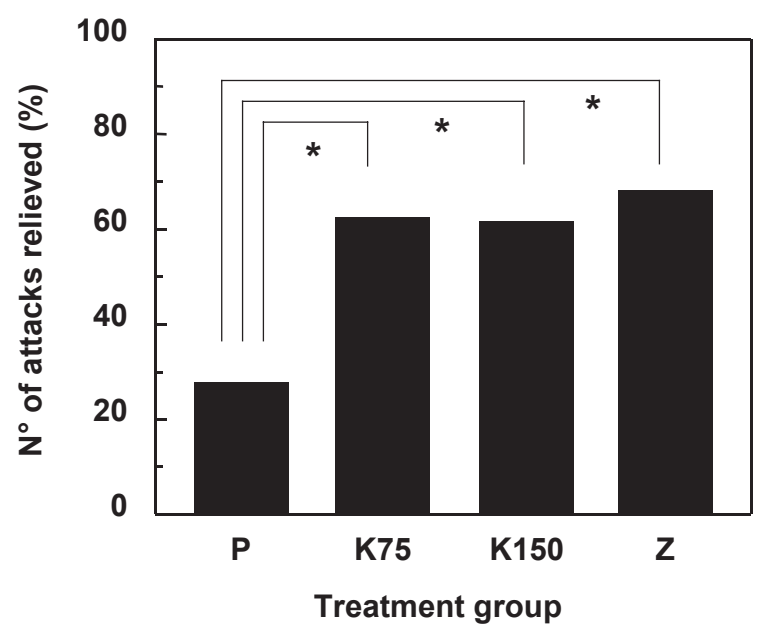

Figure 3 Relief of migraine attack in 235 patients included in a comparative study of ketoprofen and zolmitriptan using a cross-over design (Dib et al 2002). Data are given as the percentage of the total number of attacks that were reduced in severity to mild or absent at two hours. Treatment groups are placebo (P), ketoprofen $75 \mathrm{mg}$ (K75), ketoprofen $150 \mathrm{mg}(\mathrm{K})$ and zolmitriptan $2.5 \mathrm{mg}(\mathrm{Z})$. The asterisk indicates a significant difference ( $P<0.0001$; GEE model) between the bracketed groups.

\section{Triptans}

The introduction of the triptans as specific treatments for migraine headache represented an important breakthrough as these drugs were both more efficacious and better tolerated than previously available drugs (ergot alkaloids). The first demonstration of the potential benefit of triptans came from an open-label proof-of-concept study published in 1988 (Doenicke et al 1988), subsequently confirmed in two pivotal randomized controlled trials (Ensink 1991). Sumatriptan was first made available as an injectable subcutaneous formulation in 1992 and subsequently as oral tablets and as a nasal spray. Since the introduction of sumatriptan, six other members of this class have been made available. These are zolmitriptan, naratriptan, rizatriptan, eletriptan, frovatriptan and almotriptan. All triptans are $5-\mathrm{HT}_{1 \mathrm{~B} / \mathrm{D}}$ serotonin receptor agonists, acting in the cerebral vasculature to promote vasoconstriction and prevent the release of local vasoactive peptides responsible for inflammation and generation of the pain stimulus (Ferrari and Saxena 1992). Clinically, triptans have been shown to provide rapid, effective and sustained pain relief and a reduction in the intensity or duration of associated symptoms.

A meta-analysis has been performed concerning 53 clinical trials with these triptans used orally for the acute treatment of migraine (Ferrari et al 2001). This concluded that between $40 \%$ and $70 \%$ of patients treated with a triptan experienced a significant reduction in pain severity after two hours, whereas between $10 \%$ and $25 \%$ are pain-free and remain pain-free for up to 24 hours. In terms of tolerability, naratriptan and almotriptan were associated with the lowest numbers of treatment-emergent adverse events. Dose-response relationships were observed for all triptans that had been evaluated at multiple doses. Very similar conclusions were drawn from a second meta-analysis evaluating 54 clinical trials which determined efficacy in terms of numbers-needeed-to-treat (Oldman et al 2002). Another meta-analysis of 27 trials also used the numbers-needed-to-treat approach to assess cost-effectiveness, and found almotriptan to be the most cost-effective within the US healthcare system (Adelman and Belsey 2003). This has also been the conclusion of a systematic review of pharmacoeconomic studies with the triptans (Lofland and Nash 2005). However, relative cost-effectiveness can vary considerably between different healhcare systems (Belsey 2004).

There are a number of factors entering into the choice of a given triptan for acute treatment, From the patient's perspective, complete freedom from pain, rapid onset of action, no recurrence and absence of side effects are the most important criteria (Lanteri-Minet 2005). The TRIPSTAR study (Goadsby et al 2004; Lipton et al 2005a) has attempted to categorise efficacy and tolerability attributes of triptans from extensive structured interviews with physicians and migraineurs. In a second step, individual drugs could be matched to this model. On the basis of such analyses, a stepwise heierarchy for the treatment of acute migraine with triptans can be proposed (Figure 4). The best-tolerated drugs should be used (almotriptan, frovatriptan or naratriptan) as a first-line therapy. If these do not provide an adequate response, one of the other oral triptans should be tried. In case of continued treatment resistance, a nasal spray or injectable preparation should be proposed; This form is also proposed as first line in children.

\section{Prophylaxis of migraine}

Migraine prophylaxis should be considered when acute treatment is insufficient, either due to the severity of the headache disorder or to the ineffectiveness of treatment. Effective prophylaxis of migraine decreases recourse to acute treatment, thus reducing the risk of transformation to chronic headache and also decreases overall healthcare resource utilisation (Silberstein et al 2003). Guidelines proposed by the American College of Physicians (Snow et al 2002) recommend that prophylaxis be initiated in patients with two or more migraine headaches per month that produce disability lasting three or more days per month, contraindications or non-response to acute treatment, the use of relief medication more than twice a week or who present with certain specified atypical migraine disorders. Broadly similar 


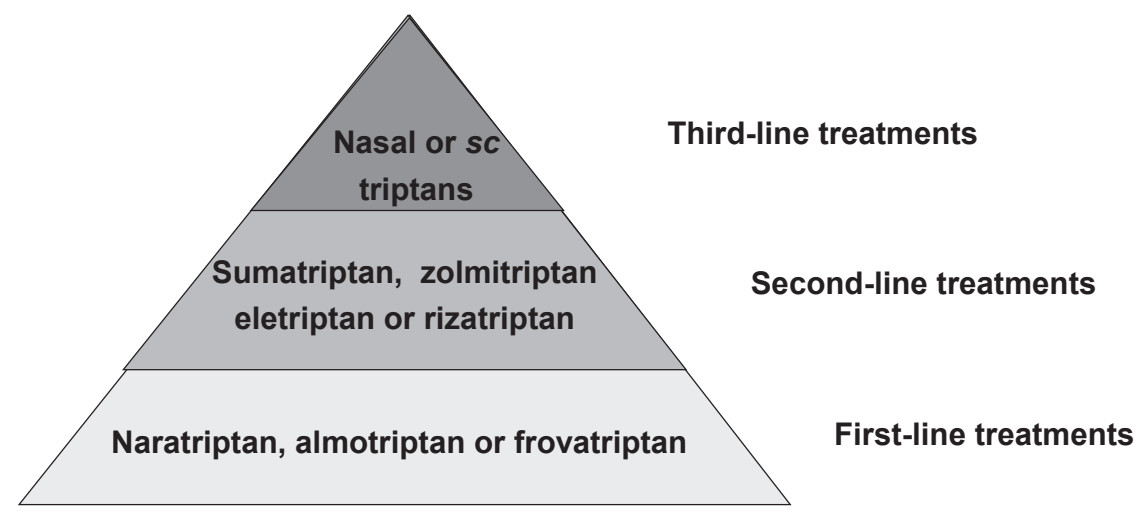

Figure 4 Treatment hierarchy for the acute treatment of migraine with triptans.

recommendations have been published in a number of other national guidelines from, for example, Germany (Diener et al 1998), the United Kingdom (Dowson et al 2002) and France (Geraud et al 2004).

The medication classes available for the prophylactic treatment of migraine are presented in Table 1. The specific prophylactic agents act by a variety of pharmacological mechanisms, and a large number of molecules have been evaluated in clinical trials of varying quality. A review of all these trials prepared by the Quality Standards Subcommittee of the American Academy of Neurology, however, identified only four agents for which there was strong evidence of high efficacy in the prophylaxis of migraine (Silberstein 2000). These four drugs were propranolol, timolol, amitriptyline and valproate.

\section{Beta-blockers}

$\beta$-Blockers represent the oldest, widest used and best-documented prophylactic treatment for migraine. The utility of propranolol was first identified quite serendipitously in 1972 (Weber and Reinmuth 1972) and since then has been the object of numerous clinical trials. A meta-analysis performed in 1991 of studies including 2403 patients included in placebo-controlled clinical trials reported a reduction of $44 \%$ in the frequency of headaches in patients receiving propranolol compared to $16 \%$ in the placebo group (Holroyd et al 1991). A more recent evidence-based review performed for the Cochrane Collaboration (Linde and Rossnagel 2004) extending the analysis to over five thousand patients included in 58 trials confirmed the superiority of proranolol to placebo in the prophylaxis of migraine. No clear dose-response relationship is observed with propranolol, necessitating up-titration of the dose until an adequate therapeutic response is observed. In most patients, this is achieved at a dose of 120-240 mg per day (Andersson and Vinge 1990). Propranolol is considered to be the reference prophylactic treatment for migraine. Other $\beta$-blockers which have demonstrated superior efficacy for migraine prophylaxis compared to placebo include metoprolol (Kangasniemi et al 1987; Steiner et al 1988), timolol (Tfelt-Hansen and Olesen 1984; Stellar et al 1984), altenolol (Forssman et al 1983; Johannsson et al 1987) and nadolol (Freitag and Diamond 1984). Comparable efficacy to propranolol has been shown for all four of these drugs (Kangasniemi and Hedman 1984; Olsson et al 1984; Tfelt-Hansen and Olesen 1984; Stensrud and Sjaastad 1980; Ryan 1984; Sudilovsky et al 1987). On the other hand,

Table I Prophylactic treatments for migraine

\begin{tabular}{ll}
\hline$\beta$-Blockers & Propranolol, metoprolol \\
$\alpha$-Adrenergic drugs & Indoramine, clonidine \\
Antiserotonergic drugs & Methysergide, pizotifen, oxeterone \\
Certain calcium channel blockers & Flunarizine \\
Certain antidepressants & Amitriptyline \\
Certain antiepileptic drugs & Valproate, topiramate \\
Ergot alkaloids & Dihydroergotamine \\
Estrogens & Estrodiol gel \\
\hline
\end{tabular}


$\beta$-blockers with partial agonist activity such as alprenolol (Ekbom 1975) or oxprenolol (Ekbom and Zetterman 1977), have not been shown to be beneficial.

The most common side-effects observed with $\beta$-blockers include nausea, dizziness, fatigue, depression and insomnia, although these are generally not severe and do not lead to treatment discontinuation. In the meta-analysis of trials with propranolol (Holroyd et al 1991), the rate of study discontinuation for whatever reason was one in six.

\section{Clonidine and other drugs acting at adrenoceptors}

There have been sixteen controlled clinical trials of clonidine for the prophylaxis of migraine. Some of these have found small but significant treatment effects, but most have not (Silberstein 2000). Two comparative studies suggest that clonidine is less efficacious than $\beta$-blockers (Kass and Nestvold 1980; Louis et al 1985).

\section{Antiserotoninergic drugs}

A number of small, relatively old clinical trials tested dihydroergotamine in the prophylaxis of migraine (Bonuso et al 1983; Bousser et al 1988; Langohr et al 1988; Martucci et al 1983; Neuman et al 1986; Pradalier et al 1988). However, a recent randomized, parallel group study versus placebo in 363 patients (Pradalier et al 2004a) which used a rigorous design following current clinical trial guidelines (Tfelt-Hansen et al 2000) did not reveal a statistically significant difference between the two treatments on the primary outcome measure (headache frequency), although differences in favor of dihydroergotamine were observed for several of the secondary efficacy measures evaluated in the study. In spite of the paucity of evidence, dihydroergotamine is one of the treatment frequently used for the prevention of migraine, for example in France (Lanteri-Minet et al 2000).

Concerning other ergot derivatives, three cross-over studies (Frediani et al 1991; Bussone et al 1999; Micieli et al 2001) have compared dihydroergocryptine to other prophylactic treatments (propranolol, flunarizine and dihydroergotamine). These studies all concluded that the drug may reduce headache frequency, but the absence of a comparison with a placebo group makes these studies difficult to interpret.

Methysergide is a semi-synthetic derivative of ergot alkaloids that is a relatively selective antagonist at 5-HT2 serotonin receptors. Methysergide was developed for the treatment of migraine in 1959 and the four clinical trials that demonstrated superior efficacy to placebo were performed in the 1960's (Lance et al 1963; Shekelle and Ostfeld 1964; Pedersen and Moller 1966; Ryan 1968). More recently, comparative studies have been performed with propranolol (Steardo et al 1982), flunarizine (Steardo et al 1986) and 5-hydroxytryptophan (Titus et al 1986). However, methysergide has severally potentially serious side-effects, notably retroperitoneal or retropleural fibrosis (Elkind et al 1968). This is generally associated with long-term, uninterrupted administration and occurs in around one out of every five thousand treated patients. For this reason, methysergide is only recommended for severe migraine that has not responded to other prophylactic treatments (Silberstein 1998). When methysergide is used, the drug should be discontinued for three to four weeks after every six months of treatment.

Pizotifen (BC105, pizotyline) is extensively used in Europe as a prophylactic treatment for migraine. This serotonin receptor antagonist has been evaluated in several randomized, double-blind studies and shown to be superior to placebo for the prevention of migraine and to reduce utilisation of acute headache relief medication (Ryan 1968; Osterman 1977; Bellavance and Meloche 1990). Head-tohead comparisons has shown its efficacy to be similar to that of the $\beta$-blocker metoprolol (Vilming et al 1985). Pizotifen has also been demonstrated to be useful for the treatment of paediatric migraine in a small placebo-controlled study (Gillies et al 1986). Like other 5-HT 2 receptor antagonists, use of pizotifen is associated with significant weight gain, and treatment discontinuation rates for side-effects are high.

Other 5-HT receptor antagonists that have been evaluated in the prevention of migraine include cyproheptadine, lisuride, oxeterone, iprazochrome, 5-hydroxytryptophan (oxitriptan) and tropisetron. With the exception of tropisetron, these agents are antagonists at 5- $\mathrm{HT}_{2}$ receptors, although most of them are relatively aspecific and also act at other monoamine receptors or ion channels. Cyproheptadine has been found to decrease the frequency of migraine attacks in a small early study (Lance et al 1970) and has subsequently become widely-used for prevention of migraine headaches in children (Bille et al 1977). Quite recently, a randomized, double-blind trial compared treatment with placebo, cyproheptadine, propranolol and the combination of the two active drugs (Rao et al 2000). Not only did this study confirm the benefit offered by cyproheptadine compared to placebo, but also indicated that the association of the two drugs resulted in a larger reduction in headache frequency than did the use of either drug alone. Lisuride was evaluated in two doubleblind, placebo-controlled clinical trials (Somerville and Herrmann 1978; Herrmann et al 1978). Interest in oxeterone 
stems from four small, double-blind studies performed in Switzerland in the late '70s (de Coster 1976; Wasserfallen 1976; Dufresne 1978; Florence 1978). Two randomized, placebo-controlled, double-blind studies of iprazochrome found the drug to be superior to placebo for the prevention of migraine (Kozubski and Prusinski 1999; Osterman 1977); in the first of these, pizotifen was also studied and found to be more effective than iprazochrome. Placebo-controlled studies with 5-hydroxytryptophan have failed to provide convincing evidence of efficacy (De Benedittis and Massei 1985; Santucci et al 1986) and comparative studies with methysergide (Titus et al 1986) and propranolol (Maissen and Ludin 1991) have found 5-hydroxytryptophan to be less effective than these two drugs. Two large, randomized, double-blind, placebo-controlled trials with the $5-\mathrm{HT}_{3}$ receptor antagonist tropisetron have yielded inconclusive results (Ferrari et al 1991).

\section{Calcium channel blockers}

Calcium channel blocking drugs have evoked much interest in the prophylactic treatment of migraine due to their vasodilator effects in the cerebral vasculature (Montastruc and Senard 1992). However, the only such drug that has demonstrated unequivocal efficacy is flunarizine, and it is debatable whether this property is related to calcium channel blockade at all. It has been suggested that a neuronal rather than a vascular action underlies its beneficial effects in migraine (Olesen 1990). This drug has been evaluated in nine placebo-controlled clinical trials, although several of these are small or of poor quality. A meta-analysis of the most robust of these trials (Reveiz-Herault et al 2003) concluded that treatment flunarizine resulted in a greater reduction in headache frequency than placebo. Comparative trials have generally demonstrated a similar effect size as that obtained with propranolol (Lucking et al 1988; Ludin 1989; Gawel et al 1992; Diener 1997) or metoprolol (Grotemeyer et al 1988; Sorensen et al 1991). One small study which investigated combination therapy with propranolol and flunarizine failed to demonstrate superior efficacy for the combination compared with monotherpay with either drug alone (Bordini et al 1997).

The side effects described for treatment with flunarizine are somnolence, weight gain, and, in less frequently, depression. Treatment discontinuation rates due to side-effects have been high in many of the clinical trials. Due to the relatively poor side-effect profile of flunarizine compared to $\beta$-blockers, the use of this drug should be reserved for secondline treatment (Montastruc and Senard 1992). Dotarizine is an analogue of flunarizine which has showed preliminary evidence of efficacy for the prophylaxis of migraine (Galiano et al 1993).

Concerning other classes of calcium channel blocker, studies with dihydropyridines have been inconclusive (Montastruc and Senard 1992). Nifedipine was found to offer no benefit over placebo in two randomized, double-blind clinical trials (McCarthy and Peroutka 1989; Shukla et al 1995), whereas nicardipine (Leandri et al 1990) was reported to be effective. For nimodipine, two positive (Gelmers 1983; Havanka-Kanniainen et al 1985), and three negative (Ansell et al 1988; MINES 1989a, 1989b) placebo-controlled studies have been reported. Study sizes were rather small in all cases. Preliminary evidence for the efficacy of verapamil has come from three small placebo-controlled trials, none of which included more than twenty-five patients (Solomon 1989). Diltiazem has not been evaluated in randomized, double-blind controlled studies. The most recently evaluated calcium channel blocker is cyclandelate, for which three placebo-controlled trials have been performed, two of which included over 200 patients (Diener et al 1996; Diener et al 2001) and did not demonstrate superior efficacy to placebo in preventing headaches. The third, smaller $(n=25)$ study did find cyclandelate to be more efficacious than placebo (Siniatchkin et al 1998).

\section{Antiepileptic drugs}

Although interest in the potential of antiepileptic drugs for the treatment of migraine headache goes back over thirty years (Rompel and Bauermeister 1970), there has been a renewal of interest in such drugs over the last decade. Most of the large randomized clinical trials in migraine prophylaxis which have used current standards of clinical trial methodology (IHSCCT 1991) have concerned this class of drug, which represents the principal innovation in the field for over twenty-five years. Antiepileptic drugs reduce neuronal excitability and thus reduce the cortical spreading depression that is believed to be an early event in the development of migraine headache (Welch 2003). A number of studies using transcranial magnetic stimulation or magnetoencephalography (Bowyer et al 2005; Mulleners et al 2002) have shown that antiepileptic drugs do effectively reduce cortical hyperexcitability in patients with migraine.

A number of antiepileptic drugs was tested over the past twenty years (Krymchantowski et al 2002; Silberstein and Goadsby 2002; Chronicle and Mulleners 2004; Young et al 2004). These include valproate, topiramate, gabapentin, lamotrigine, carbamazepine, clonazepam, tiagabine, 
leviracetam and zonisamide. Recent, large-scale controlled trials are however limited to the first four drugs, and only valproate and topiramate have been approved for the prophylaxis of acute migraine in some countries. Studies performed with tiagabine (Drake et al 1999; Freitag et al 1999), levetiracetam (Drake et al 2001; Krusz 2001a) and zonisamide (Drake et al 2001; Krusz 2001b) did not include a control group and thus allow no conclusions to be drawn as to their real clinical benefit.

The first clinical trial dates from 1970, when Rompel and Bauermeister (1970) evaluated the efficacy of carbamazepine in a randomized, placebo-controlled, cross over study, and observed an improvement in $84 \%$ of patients during treatment with carbamazepine compared to $27 \%$ during the placebo phase, and a corresponding reduction in the number of migraine attacks from 186 under placebo to 30 under carbamazepine.

The first study evaluating the efficacy of valproate, and using a placebo-controlled double-blind randomized cross-over design in twenty-nine patients (Hering and Kuritzky 1992). Patients received a low dose of valproate $(400 \mathrm{mg}$ ) for eight weeks. Reduction of the frequency, severity and duration of migraine attacks was observed in $86.2 \%$ of the patients studied. A number of subsequent randomized, controlled studies have valproate in the prophylaxis of migraine headache (Jensen et al 1994; Mathew et al 1995; Klapper 1997; Freitag et al 2002), and concluded that this drug is an efficacious, well-tolerated and easy-to-use medication. Notably, the findings were replicated in a much larger study including 107 patients and using a parallel-group design (Mathew et al 1995). A reduction of at least $50 \%$ in headache frequency compared to baseline was observed in $48 \%$ of patients receiving valproate compared to $14 \%$ of those receiving placebo. The severity of residual headaches was also reduced in the valproate treatment group. However, there was a higher rate of adverse events and of treatment discontinuation in patients receiving valproate. A dose-ranging study comparing fixed doses of $500 \mathrm{mg}, 1000 \mathrm{mg}$, or $1500 \mathrm{mg}$ with placebo (Klapper 1997) showed similar efficacy between all three doses, and recommended that the $500 \mathrm{mg} /$ day dose should be used in most patients. A subsequent study, in which responses were related to plasma levels of valproate, also concluded that for most patients, doses over $600 \mathrm{mg} /$ day would provide no additional benefit over lower doses.

It should be noted that intravenous valproate has also been evaluated in several randomized, controlled studies (Edwards et al 2001; Tanen et al 2003; Leniger et al 2005) for the acute treatment of migraine, following the publication of an extensive uncontrolled case series suggesting the interest of such a treatment (Mathew et al 2000). Although efficacious, it appeared less active than intravenous lysine-acetylsalicylic acid or prochlorperazine. The tolerability and commodity of use of intravenous valproate in this indication are obviously inferior compared to triptans or NSAIDS and this treatment is unlikely to be of widespread use.

Although treatment with valproate is generally well-tolerated, this drug is associated with an elevated teratogenic risk (Tomson and Battino 2005). In patients with epilepsy, this risk has been estimated in a number of dedicated retrospective and prospective surveys. For example, in a recent analysis of data from the Swedish Medical Birth Registry and the Swedish Registry of Congenital Malformations, the rate of major malformations in neonates exposed to valproate in utero was $9.7 \%$ compared to $1.0 \%$ in the Swedish general population (Wide et al 2004). There is some evidence that this risk is dose-related, being particularly high with valproate doses over $800-1000 \mathrm{mg} /$ day. In patients with migraine, of whom women of child-bearing age represent the majority, this risk clearly needs to be taken into account in assessing the risks and benefits of treatment with valproate. Unlike what is observed for epilepsy, where this may be the only drug that offers complete seizure freedom, in migraine, valproate is just one of a number of agents that offers a similar level of headache relief.

The most data on the utility of antiepileptic drugs in the prophylaxis of migraine has been obtained for topiramate. The interest of this drug was first suggested in a series of open-label studies (Krusz and Scott 1999; Mathew et al 2002; Schuaib et al 1999; Von Seggern et al 2002; Young et al 2002) and subsequently confirmed in two randomized controlled pilot studies (Storey et al 2001; Edwards et al 2003).

Two large pivotal randomized Phase III clinical trials were performed and the results used to obtain marketing authorisation for topiramate. These evaluated three doses of topiramate $(50 \mathrm{mg} /$ day, $100 \mathrm{mg} /$ day and $200 \mathrm{mg} /$ day) in over 900 adult subjects using an identical design (Brandes et al 2004; Silberstein et al 2004). These studies demonstrated a reduction in the monthly frequency of migraine headaches of $30 \%$ to $50 \%$ following initiation of topiramate treatment (Figure 5). The effect of topiramate was dose-related and usually was observable within the first month of treatment. Since then, several other randomized, controlled studies have generated data largely consistent with the results of the pivotal studies (Silvestrini et al 2003; Diener et al 2004b; Mei et al 2004). 


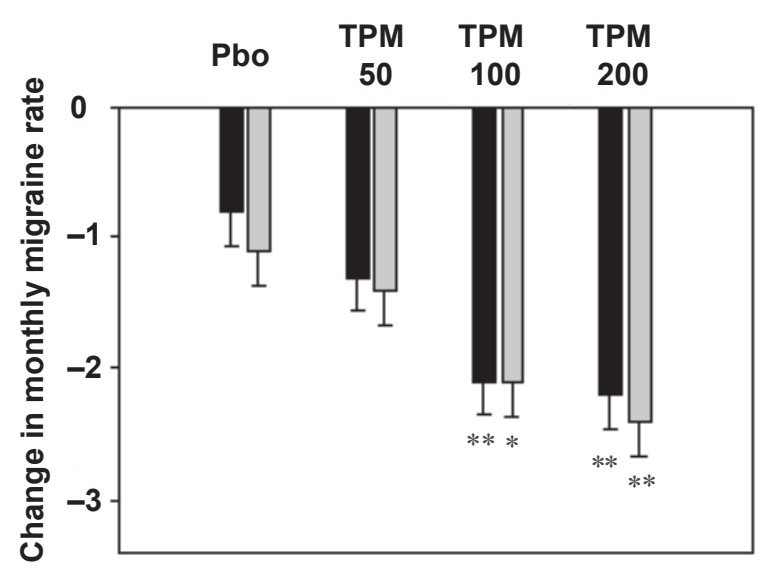

Figure 5 Efficacy of topiramate in the prophylaxis of migraine. Three different doses of topiramate (TPM; $50 \mathrm{mg} / \mathrm{day}, 100 \mathrm{mg} /$ day, and $200 \mathrm{mg} /$ day) are compared with placebo (Pbo). Data represent the change in monthly migraine frequency compared to a pre-treatment baseline period. The asterisks indicate a statistically significant difference from placebo ( $\left.{ }^{*} \mathrm{p}<0.01 ;{ }^{* *} \mathrm{p}<00 \mathrm{I}\right)$. Data are taken from Brandes and colleagues (2004) (grey columns) and Silberstein and colleagues (2004) (black columns).

However, a number of potentially serious side-effects are associated with topiramate (Jones 1998), and it is important to consider safety issues carefully before and during treatment of patients with migraine with this antiepileptic drug. Many of these side-effects are related to inhibition of carbonic anhydrase, including metabolic acidosis, formation of kidney stones, acute myopia associated with secondary angle closure glaucoma, paraesthesia and oligohidrosis. In addition, impairments of cognitive function (slowing of thought processes) and fatigue are commonly reported. Topiramate use is also associated with significant weight loss, which may also be detrimental to self-image and quality of life. The incidence of these side-effects appears to be dose-related and can be mitigated by slowly titrating the dose upwards.

Two randomized, placebo-controlled studies have assessed the efficacy and safety of gabapentin in the prophylaxis of migraine. One study evaluated doses of $900 \mathrm{mg}$ /day to $2400 \mathrm{mg} /$ day and included 143 subjects (Mathew et al 2001), whilst the other evaluated a fixed dose of $1200 \mathrm{mg}$ /day in 63 subjects (Di Trapani et al 2000). The larger study demonstrated a higher proportion of patients achieving a reduction in the monthly migraine rate of at least $50 \%$ in the gabapentin-treated patients compared to those receiving placebo, and a significant reduction in the frequency and severity of migraine headaches was reported in the smaller study. Nonetheless, somnolence and dizziness were observed in a significant minority of patients. A subsequent randomized, open-label study found essentially similar findings (Jimenez-Hernandez et al 2002).

Lamotrigine has been studies in three open-label studies (D’Andrea et al 1999; Lampl et al 1999; Pascual et al 2004) and one randomized, placebo controlled study (Steiner et al 1997). Although the open-label studies suggested that lamotrigine could be of benefit, particularly in relieving aura, the placebo-controlled study, which included 110 patients, found no evidence that the efficacy of lamotrigine was superior to placebo.

Clonazepam has been evaluated in a small, randomized, placebo-controlled double-blind, cross-over study (Stensrud and Sjaastad 1979). This alternated four-week treatment-free run-in periods with four-week treatment periods where the patients received placebo, clonazepam $1 \mathrm{mg}$ or clonazepam $2 \mathrm{mg}$. A significant reduction in headache frequency compared to the run-in period was observed for the two clonazepam-treatment periods but not for the placebo period.

Compared with $\beta$-blockers, randomized clinical trials of valproate (Kaniecki 1997) and topiramate (Diener et al 2004b) have shown these two drugs to have similar efficacy to propranolol, although the $\beta$-blocker was better tolerated. Due to this difference in tolerability, antiepileptic drugs should be considered principally as second-line treatments in patients who have failed to respond adequately to $\beta$-blockers. There is little information on the utility of combining antiepileptic drugs and $\beta$-blockers. An open-label study which evaluated the combination of propranolol or nadolol with valproate in 52 subjects who had failed to respond to the individual drugs in monotherapy (Pascual et al 2003). This study demonstrated that over half the treated subjects responded to the combination treatment. A second open-label study investigated add-on treatment with topiramate in patients who responded inadequately to current prophylactic treatment, principally with propranolol or flunarizine 
(Martinez et al 2003). Again, headache frequency decreased after initiation of combination treatment. These interesting observations deserve confirmation in randomized, double-blind studies.

\section{Antidepressants}

The utility of certain antidepressants for the prophylaxis of migraine dates from the only 1970s (Gomersall and Stuart 1973). The most widely studied antidepressant is amitriptyline and this agent appears to be the most efficacious (Colombo et al 2004). It is possible that amitriptyline is active in the prophylaxis of migraine by virtue of an action at voltage-sensitive ion channels controlling neuronal excitability. However, this drug causes sedation which may not be desirable in patients taking this drug every day for migraine prophylaxis. In this respect, other antidepressants with a more acceptable side-effect profile may be preferred. For example, venlafaxine was shown to be reduce headache frequency in a retrospective case series (Adelman et al 2000) and has since shown similar efficacy to amitriptyline and superior efficacy to placebo in two recent randomized, double-blind studies (Bulut et al 2004; Ozyalcin et al 2005).

Other older antidepressants for which there is some evidence for efficacy in the prophylaxis of migraine include clomipramine (Noone 1980; Langohr et al 1985), opipramol (Jacobs 1972) and mianserin (Monro et al 1985). However, these relatively old studies generally included small numbers of patients, were not always double-blinded, and did not use the design and outcome criteria currently recommended for randomized clinical trials in migraine (Tfelt-Hansen et al 2000).

The utility of selective-serotonin reuptake inhibitors in the prophylaxis of migraine is much less clear. Early studies performed in the 1980's in Scandinavia failed to demonstrate clear efficacy for femoxitine (Andersson and Petersen 1981; Zeeberg et al 1981; Kangasniemi et al 1983; Orholm et al 1986) and more recent studies with sertraline (Landy et al 1999) and citalopram have also been disappointing (Rampello et al 2004). On the other hand, there is some weak evidence for the efficacy of fluvoxamine (Bank 1994) and fluoxetine (Adly et al 1992; Saper et al 1995; Steiner et al 1998; d'Amato et al 1999).

Of particular interest is the use of amitriptyline, and potentially other antidepressants, in the treatment of chronic daily headache. A meta-analysis of thirty-eight clinical trials (Tomkins et al 2001) concluded that all classes of antidepressant drug evaluated (tricyclics, selective serotonin reuptake inhibitors and serotonin receptor antagonists) were all effective in reducing the frequency of both migraine-type and tension-type chronic daily headaches with an effective size that was considered as large. This allowed a reduction in the use of analgesics as headache relief medication. Since analgesic use is considered to be an important factor in the development and maintenance of chronic headaches, and a major determinant of poor prognosis, prophylaxis with antidepressants may improve clinical outcome over the long-term as well as reducing headache frequency in the short-term.

\section{Hormone therapy for menstrual migraine}

Oral contraception with progestins can be effective in reducing the frequency of menstrual migraine headaches (Bradley et al 1968; Somerville and Carey 1970), presumably by suppression of the menstrual cycle. However, oral contraceptive regimens using continuous progestin exposure seem interesting but are no longer widely used, and current standard oral contraceptives have not been found to be particularly efficacious (Silberstein and Merriam 1999). Use of long-acting estrogen preparations such as gels (de Lignieres et al 1986; Dennerstein et al 1988; MacGregor and Hackshaw 2002; MacGregor et al 2006) or patches (de Lignieres and Bousser 1992; Pfaffenrath 1993; Pradalier et al 2004b) have also been reported to be effective for migraine prophylaxis and may be more suitable formulations in this indication. These estrogens initiated at the end of the luteal phase and maintained until the end of the menstrual period compensate for the rapid fall of endogenous estrogen concentrations that is thought to precipitate migraine headaches. Two small clinical trials of phytoestrogens (Burke et al 2002; Ferrante et al 2004) suggested that these agents may also be effective in the treatment of menstrual migraine.

\section{Conclusions}

Advances in our understanding of the pathophysiology of migraine have resulted in important breakthroughs in treatment. Notably, understanding of the role of serotonin in the cerebrovascular circulation led to the development of triptans for the acute relief of migraine headaches, and the identification of cortical spreading depression as an early central event associated wih migraine has brought renewed interest in antiepileptic drugs for migraine prophylaxis.

Nevertheless, several important questions remain. Firstly, while it is increasingly recognized that migraine is not a single disease but rather a syndrome that can manifest itself in a variety of pathological conditions, the consequences of this for treatment are not understood. Clinical research needs to be devoted to identifying which sort of patients benefit best from 
which treatments, particularly in the field of prophylaxis. One possible approach that merits exploration is to try and match prophylactic treatments to particular patterns of precipitating factors, as has already proved successful for the treatment of menstrual migraine In this respect, the proposal of four types of migraine (adrenergic, serotoninergic, menstrual, and muscular) may contribute to the optimisation of migraine prophylaxis.

The interest of stratifying treatment strategies by headache severity is also at an early stage. Studies such as DISC (Lipton et al 2000b; Sculpher et al 2002) suggest that this could be a useful approach, but treatment stratification remains underexploited in routine care of patients with migraine. Further prospective studies would help characterising patient severity groups that would benefit from particular strategies.

Treatment resistance is frequent with both acute and prophylactic treatments of migraine. Even with triptans, probably the most effective class of antimigraine drug, up to one-third of patients fail to respond adequately. The reasons underlying treatment resistance need to be better understood, and strategies identified to avoid serial treatment failures when the patient first comes to the clinic.

Moreover, there is a lack of information on the benefit of combination treatment using different drug classes. This approach may be of particular use in patients with more severe hedaches and in those showing mixed headache types. In this respect, and bearing in mind potential artefacts due to the open-label design of the study, the results of the combination study with propranolol and valproate imply that these two agents can be used in association to provide greater efficacy in particular patients. Further studies such as this using a randomized, double-blind design are required to provide the data necessary to orientate treatment decisions about combinations of migraine prophylaxis agents.

Finally, little is known about long-term outcome in treated migraine. It is possible that appropriate early prophylaxis may modify the long-term course of the disease and avoid late complications, as has been shown, for example, in another paroxystic neurological condition, epilepsy. This is particularly relevant for antiepileptic drugs that are thought to be of benefit in migraine by an action on cortical excitability. If this is the case, then early aggressive migraine prophylaxis may be merited. Although medication overuse can be a predisposing factor to developing a chronic headache syndrome, risk thresholds remain poorly quantified, particularly for specific acute migraine treatments such as the triptans.

Although migraine is much better defined than it was twenty years ago, and more efficacious and better tolerated treatments are on offer, there is still a long way to go before we can provide patients with individualized and rational long-term therapeutic management strategies that take into account the heterogeneity of the migraine condition and its variable clinical course.

\section{Disclosure}

The author reports no conflicts of interest in this work.

\section{References}

Abu-Arefeh I, Russell G. 1994. Prevalence of headache and migraine in schoolchildren. Br Med J, 309:765-9.

Adelman JU, Belsey J. 2003. Meta-analysis of oral triptan therapy for migraine: number needed to treat and relative cost to achieve relief within 2 hours. J Manag Care Pharm, 9:45-52.

Adelman LC, Adelman JU, Von Seggern R, et al. 2000. Venlafaxine extended release (XR) for the prophylaxis of migraine and tensiontype headache: A retrospective study in a clinical setting. Headache, 40:572-80.

Adly C, Straumanis J, Chesson A. 1992. Fluoxetine prophylaxis of migraine. Headache, 32:101-4.

Andersson KE, Vinge E. 1990. Beta-adrenoceptor blockers and calcium antagonists in the prophylaxis and treatment of migraine. Drugs, 39:355-73.

Andersson PG, Petersen EN. 1981. Propranolol and femoxetine, a HT-uptake inhibitor, in migraine prophylaxis. A double-blind crossover study. Acta Neurol Scand, 64:280-8.

Annequin D, Tourniaire B, Massiou H. 2000. Migraine and headache in childhood and adolescence. Pediatr Clin North Am, 47:617-31.

Ansell E, Fazzone T, Festenstein R, et al. 1988. Nimodipine in migraine prophylaxis. Cephalalgia, 8:269-72.

Bank J. 1994. A comparative study of amitriptyline and fluvoxamine in migraine prophylaxis. Headache, 34:476-8.

Bellavance AJ, Meloche JP. 1990. A comparative study of naproxen sodium, pizotyline and placebo in migraine prophylaxis. Headache, 30:710-5.

Belsey JD. 2004. Cost effectiveness of oral triptan therapy: a trans-national comparison based on a meta-analysis of randomised controlled trials. Curr Med Res Opin, 20:659-69.

Bigal ME, Bordini CA, Speciali JG. 2002. [Intramuscular diclofenac in the acute treatment of migraine: a double-blind placebo controlled study]. Arq Neuropsiquiatr, 60:410-5.

Bille B, Ludvigsson J, Sanner G. 1977. Prophylaxis of migraine in children. Headache, 17:61-3.

Bonuso S, Di Stasio E, Barone P, et al. 1983. Timed-release dihydroergotamine in the prophylaxis of mixed headache. A study versus amitriptyline. Cephalalgia, 3(Suppl 1):175-8.

Bordini CA, Arruda MA, Ciciarelli MC, et al. 1997. Propranolol vs flunarizine vs flunarizine plus propranolol in migraine without aura prophylaxis. A double-blind trial. Arq Neuropsiquiatr, 55:536-41.

Boureau F, Joubert JM, Lasserre V, et al. 1994. Double-blind comparison of an acetaminophen $400 \mathrm{mg}$-codeine $25 \mathrm{mg}$ combination versus aspirin $1000 \mathrm{mg}$ and placebo in acute migraine attack. Cephalalgia, 14:156-61.

Bousser MG, Chick J, Fuseau E, et al. 1988. Combined low-dose acetylsalicylic acid and dihydroergotamine in migraine prophylaxis. A double-blind, placebo-controlled crossover study. Cephalalgia, 8:187-92.

Bowyer SM, Mason KM, Moran JE, et al. 2005. Cortical hyperexcitability in migraine patients before and after sodium valproate treatment. J Clin Neurophysiol, 22:65-7.

Bradley WG, Hudgson P, Foster JB, et al. 1968. Double-blind controlled trial of a micronized preparation of flumedroxone (Demigran) in prophylaxis of migraine. $\mathrm{Br} \mathrm{Med} J, 3: 531-3$. 
Brandes JL, Saper JR, Diamond M, et al. 2004. Topiramate for migraine prevention: a randomized controlled trial. JAMA, 291:965-73.

Brennum J, Brinck T, Schriver L, et al. 1996. Sumatriptan has no clinically relevant effect in the treatment of episodic tension-type headache. Eur J Neurol, 3:23-28.

Bulut S, Berilgen MS, Baran A, et al. 2004. Venlafaxine versus amitriptyline in the prophylactic treatment of migraine: randomized, double-blind, crossover study. Clin Neurol Neurosurg, 107:44-8.

Burke BE, Olson RD, Cusack BJ. 2002. Randomized, controlled trial of phytoestrogen in the prophylactic treatment of menstrual migraine. Biomed Pharmacother, 56:283-8.

Bussone G, Cerbo R, Martucci N, et al. 1999. Alpha-dihydroergocryptine in the prophylaxis of migraine: a multicenter double-blind study versus flunarizine. Headache, 39:426-31.

Cao YQ, Tsien RW. 2005. Effects of familial hemiplegic migraine type 1 mutations on neuronal $\mathrm{P} / \mathrm{Q}$-type $\mathrm{Ca} 2^{+}$channel activity and inhibitory synaptic transmission. Proc Natl Acad Sci U S A, 102:2590-5.

Carey MP, Billing AE, Fry JP. 1992. Fluctuations in responses to diazepam during the oestrous cycle in the mouse. Pharmacol Biochem Behav, 41:719-25.

Castillo J, Munoz P, Guitera V, et al. 1999. Epidemiology of chronic daily headache in the general population. Headache, 39:190-6.

Chabriat H, Joire JE, Danchot J, et al. 1994. Combined oral lysine acetylsalicylate and metoclopramide in the acute treatment of migraine: a multicentre double-blind placebo-controlled study. Cephalalgia, 14:297-300

Chronicle E, Mulleners W. 2004. Anticonvulsant drugs for migraine prophylaxis. Cochrane Database Syst Rev, 3:CD003226.

Codispoti JR, Prior MJ, Fu M, et al. 2001. Efficacy of nonprescription doses of ibuprofen for treating migraine headache. a randomized controlled trial. Headache, 41:665-79.

Colombo B, Annovazzi PO, Comi G. 2004. Therapy of primary headaches: the role of antidepressants. Neurol Sci, 25(Suppl 3):S171-5.

Couturier EG, Bomhof MA, Neven AK, et al. 2003. Menstrual migraine in a representative Dutch population sample: prevalence, disability and treatment. Cephalalgia, 23:302-8.

d'Amato CC, Pizza V, Marmolo T, et al. 1999. Fluoxetine for migraine prophylaxis: a double-blind trial. Headache, 39:716-9.

D'Andrea G, Granella F, Cadaldini M, et al. 1999. Effectiveness of lamotrigine in the prophylaxis of migraine with aura: an open pilot study. Cephalalgia, 19:64-6.

Dahlof C, Bjorkman R. 1993. Diclofenac-K (50 and $100 \mathrm{mg}$ ) and placebo in the acute treatment of migraine. Cephalalgia, 13:117-23.

De Benedittis G, Massei R. 1985. Serotonin precursors in chronic primary headache. A double-blind cross-over study with L-5-hydroxytryptophan vs placebo. J Neurosurg Sci, 29:239-48.

de Coster J. 1976. [Oxetorone in the treatment of migrainous cephalalgia]. Schweiz Rundsch Med Prax, 65:879-82.

de Lignieres B, Bousser MG. 1992. Migraine. Lancet, 340:61-2.

de Lignieres B, Vincens M, Mauvais-Jarvis P, et al. 1986. Prevention of menstrual migraine by percutaneous oestradiol. $\mathrm{Br}$ Med J (Clin Res Ed), 293:1540.

Dennerstein L, Morse C, Burrows G, et al. 1988. Menstrual migraine: a double-blind trial of percutaneous estradiol. Gynecol Endocrinol, 2:113-20.

Di Trapani G, Mei D, Marra C, et al. 2000. Gabapentin in the prophylaxis of migraine: a double-blind randomized placebo-controlled study. Clin Ter, 151:145-8.

Diaz-Veliz G, Butron S, Benavides MS, et al. 2000. Gender, estrous cycle, ovariectomy, and ovarian hormones influence the effects of diazepam on avoidance conditioning in rats. Pharmacol Biochem Behav, 66:887-92.

Dib M, Massiou H, Weber M, et al. 2002. Efficacy of oral ketoprofen in acute migraine: a double-blind randomized clinical trial. Neurology, 58:1660-5.

Diener HC. 1997. [Migraine-diagnosis, differential diagnosis and therapy]. Ther Umsch, 54:64-70.
Diener HC. 1999. Efficacy and safety of intravenous acetylsalicylic acid lysinate compared to subcutaneous sumatriptan and parenteral placebo in the acute treatment of migraine. A double-blind, double-dummy, randomized, multicenter, parallel group study. The ASASUMAMIG Study Group. Cephalalgia, 19:581-8; discussion 542.

Diener HC, Brune K, Gerber WD, et al. 1998. [Treatment of migraine attacks and migraine prophylaxis: recommendations of the German Migraine and Headache Society]. Med Monatsschr Pharm, 21:30-9.

Diener HC, Bussone G, de Liano H, et al. 2004a. Placebo-controlled comparison of effervescent acetylsalicylic acid, sumatriptan and ibuprofen in the treatment of migraine attacks. Cephalalgia, 24:947-54.

Diener HC, Foh M, Iaccarino C, et al. 1996. Cyclandelate in the prophylaxis of migraine: a randomized, parallel, double-blind study in comparison with placebo and propranolol. The Study group. Cephalalgia, 16:441-7.

Diener HC, Krupp P, Schmitt T, et al. 2001. Cyclandelate in the prophylaxis of migraine: a placebo-controlled study. Cephalalgia, 21:66-70.

Diener HC, Tfelt-Hansen P, Dahlof C, et al. 2004b. Topiramate in migraine prophylaxis - results from a placebo-controlled trial with propranolol as an active control. $J$ Neurol, 251:943-50.

Doenicke A, Brand J, Perrin VL. 1988. Possible benefit of GR43175, a novel 5-HT1-like receptor agonist, for the acute treatment of severe migraine. Lancet, 1:1309-11.

Dowson AJ, Dodick DW, Limmroth V. 2005. Medication overuse headache in patients with primary headache disorders: epidemiology, management and pathogenesis. CNS Drugs, 19:483-97.

Dowson AJ, Lipscombe S, Sender J, et al. 2002. New guidelines for the management of migraine in primary care. Curr Med Res Opin, 18:414-39.

Drake M, Greathouse N, Armentbright A, et al. 2001. Levetiracetam for preventive treatment of migraine [abstract]. Cephalalgia, 21:373.

Drake M, Kay A, Knapp M, et al. 1999. An open-label trial of tiagabine for migraine prophylaxis [abstract]. Headache, 39:352.

Drake ME, Greathouse NI, Armentbright AD, et al. 2001. Preventive treatment of migraine with zonisamide [abstract]. Cephalalgia, $21: 374$

Dufresne JJ. 1978. [Double-blind study of oxetorone in patients with migraine or migrainous headache]. Schweiz Rundsch Med Prax, 67:1148-52.

Edwards KR, Norton J, Behnke M. 2001. Comparison of intravenous valproate versus intramuscular dihydroergotamine and metoclopramide for acute treatment of migraine headache. Headache, 41:976-80.

Edwards KR, Potter DL, Wu SC, et al. 2003. Topiramate in the preventive treatment of episodic migraine: a combined analysis from pilot, doubleblind, placebo-controlled trials. CNS Spectr, 8:428-32.

Ekbom K. 1975. Alprenolol for migraine prophylaxis. Headache, 15:129-32.

Ekbom K, Zetterman M. 1977. Oxprenolol in the treatment of migraine. Acta Neurol Scand, 56:181-4.

Elkind AH, Friedman AP, Bachman A, et al. 1968. Silent retroperitoneal fibrosis associated with methysergide therapy. JAMA, 206:1041-4.

Ensink FB. 1991. Subcutaneous sumatriptan in the acute treatment of migraine. Sumatriptan International Study Group. J Neurol, 238(Suppl 1):S66-9.

Epstein MT, Hockaday JM, Hockaday TD. 1975. Migraine and reporoductive hormones throughout the menstrual cycle. Lancet, 1:543-8.

Facchinetti F, Nappi RE, Tirelli A, et al. 2002. Hormone supplementation differently affects migraine in postmenopausal women. Headache, 42:924-9.

Ferrante F, Fusco E, Calabresi P, et al. 2004. Phyto-oestrogens in the prophylaxis of menstrual migraine. Clin Neuropharmacol, 27:137-40

Ferrari MD, Roon KI, Lipton RB, et al. 2001. Oral triptans (serotonin 5-HT(1B/1D) agonists) in acute migraine treatment: a meta-analysis of 53 trials. Lancet, 358:1668-75.

Ferrari MD, Saxena PR. 1992. Clinical effects and mechanism of action of sumatriptan in migraine. Clin Neurol Neurosurg, 94 Suppl:S73-7. 
Ferrari MD, Wilkinson M, Hirt D, et al. 1991. Efficacy of ICS 205-930, a novel 5-hydroxytryptamine3 (5-HT3) receptor antagonist, in the prevention of migraine attacks. A complex answer to a simple question. ICS 205-930 Migraine Study Group. Pain, 45:283-91.

Florence J. 1978. [Clinical study of oxetorone in catamenial migraine. Comparison of two posological diagrams]. Schweiz Rundsch Med Prax, 67:1323-7.

Forssman B, Lindblad CJ, Zbornikova V. 1983. Atenolol for migraine prophylaxis. Headache, 23:188-90.

Frediani F, Grazzi L, Zanotti A, et al. 1991. Dihydroergokryptine versus dihydroergotamine in migraine prophylaxis: a double-blind clinical trial. Cephalalgia, 11:117-21.

Freitag F, Diamond S, Solomon G. 1999. The prophylaxis of migraine with the GABA-agonist tiagabine: a clinical report [abstract]. Cephalalgia, 19:354.

Freitag FG, Collins SD, Carlson HA, et al. 2002. A randomized trial of divalproex sodium extended-release tablets in migraine prophylaxis. Neurology, 58:1652-9.

Freitag FG, Diamond S. 1984. Nadolol and placebo comparison study in the prophylactic treatment of migraine. J Am Osteopath Assoc, 84:343-7.

Galiano L, Matías-Guiu J, Horga J, et al. 1993. Dotarizine: a double-blind trial in propylactic treatment of migraine. Cephalalgia, 13(Suppl 13):251.

Gawel MJ, Kreeft J, Nelson RF, et al. 1992. Comparison of the efficacy and safety of flunarizine to propranolol in the prophylaxis of migraine. Can J Neurol Sci, 19:340-5.

Gelmers HJ. 1983. Nimodipine, a new calcium antagonist, in the prophylactic treatment of migraine. Headache, 23:106-9.

Geraud G, Compagnon A, Rossi A. 2002. Zolmitriptan versus a combination of acetylsalicylic acid and metoclopramide in the acute oral treatment of migraine: a double-blind, randomised, three-attack study. Eur Neurol, 47:88-98.

Geraud G, Lanteri-Minet M, Lucas C, et al. 2004. French guidelines for the diagnosis and management of migraine in adults and children Clin Ther, 26:1305-18.

Gillies D, Sills M, Forsythe I. 1986. Pizotifen (Sanomigran) in childhood migraine. A double-blind controlled trial. Eur Neurol, 25:32-5.

Goadsby PJ, Dodick DW, Ferrari MD, et al. 2004. TRIPSTAR: prioritizing oral triptan treatment attributes in migraine management. Acta Neurol Scand, 110:137-43.

Gomersall JD, Stuart A. 1973. Amitriptyline in migraine prophylaxis. Changes in pattern of attacks during a controlled clinical trial. J Neurol Neurosurg Psychiatry, 36:684-90.

Granella F, Sances G, Allais G, et al. 2004. Characteristics of menstrual and nonmenstrual attacks in women with menstrually related migraine referred to headache centres. Cephalalgia, 24:707-16.

Granella F, Sances G, Zanferrari C, et al. 1993. Migraine without aura and reproductive life events: a clinical epidemiological study in 1300 women. Headache, 33:385-9.

Grotemeyer KH, Schlake HP, Husstedt IW. 1988. [Prevention of migraine with metoprolol and flunarizine. A double-blind crossover study]. Nervenarzt, 59:549-52.

Hamalainen ML, Hoppu K, Valkeila E, et al. 1997. Ibuprofen or acetaminophen for the acute treatment of migraine in children: a double-blind, randomized, placebo-controlled, crossover study. Neurology, 48:103-7.

Havanka-Kanniainen H, Hokkanen E, Myllyla VV. 1985. Efficacy of nimodipine in the prophylaxis of migraine. Cephalalgia, 5:39-43.

[HCCIHS] Headache Classification Committee of the International Headache Society. 1988. Classification and diagnostic criteria for headache disorders, cranial neuralgias and facial pain. Cephalalgia, 8(Supp1 7):1-96.

[HCCIHS] Headache Classification Committee of the International Headache Society. 2004. Classification and diagnostic criteria for headache disorders, cranial neuralgias and facial pain. Second Edition. Cephalalgia, 24(Suppl 1):1-160.

Henry P, Auray JP, Gaudin AF, et al. 2002. Prevalence and clinical characteristics of migraine in France. Neurology, 59:232-7.
Henry P, Hiesse-Provost O, Dillenschneider A, et al. 1995. [Efficacy and tolerance of an effervescent aspirin-metoclopramide combination in the treatment of a migraine attack. Randomized double-blind study using a placebo]. Presse Med, 24:254-8.

Hering R, Kuritzky A. 1992. Sodium valproate in the prophylactic treatment of migraine: a double-blind study versus placebo. Cephalalgia, 12:81-4.

Herrmann WM, Kristof M, Sastre M, et al. 1978. Preventive treatment of migraine headache with a new isoergolenyl derivative. J Int Med Res, 6:476-82.

Holroyd KA, Penzien DB, Cordingley GE. 1991. Propranolol in the management of recurrent migraine: a meta-analytic review. Headache, 31:333-40.

International Headache Society Committee on Clinical Trials in Migraine. 1991. Guidelines for controlled trials of drugs in migraine. First edition. Cephalalgia, 11:1-12.

Jacobs H. 1972. A trial of opipramol in the treatment of migraine. J Neurol Neurosurg Psychiatry, 35:500-4.

Jensen R, Brinck T, Olesen J. 1994. Sodium valproate has a prophylactic effect in migraine without aura: a triple-blind, placebo-controlled crossover study. Neurology, 44:647-51.

Jimenez-Hernandez MD, Torrecillas Narvaez MD, Friera Acebal G. 2002. [Effectiveness and safety of gabapentin in the preventive treatment of migraine]. Rev Neurol, 35:603-6.

Johannsson V, Nilsson LR, Widelius T, et al. 1987. Atenolol in migraine prophylaxis a double-blind cross-over multicentre study. Headache, 27:372-4.

Jones MW. 1998. Topiramate--safety and tolerability. Can J Neurol Sci, 25:S13-5.

Kangasniemi P, Andersen AR, Andersson PG, et al. 1987. Classic migraine: effective prophylaxis with metoprolol. Cephalalgia, 7:231-8.

Kangasniemi P, Hedman C. 1984. Metoprolol and propranolol in the prophylactic treatment of classical and common migraine. A double-blind study. Cephalalgia, 4:91-6.

Kangasniemi PJ, Nyrke T, Lang AH, et al. 1983. Femoxetine - a new 5-HT uptake inhibitor - and propranolol in the prophylactic treatment of migraine. Acta Neurol Scand, 68:262-7.

Kaniecki RG. 1997. A comparison of divalproex with propranolol and placebo for the prophylaxis of migraine without aura. Arch Neurol, 54:1141-5.

Karachalios GN, Fotiadou A, Chrisikos N, et al. 1992. Treatment of acute migraine attack with diclofenac sodium: a double-blind study. Headache, 32:98-100.

Kass B, Nestvold K. 1980. Propranolol (Inderal) and clonidine (Catapressan) in the prophylactic treatment of migraine. A comparative trial. Acta Neurol Scand, 61:351-6.

Kavuk I, Katsarava Z, Selekler M, et al. 2004. Clinical features and therapy of medication overuse headache. Eur J Med Res, 9:565-9.

Kellstein DE, Lipton RB, Geetha R, et al. 2000. Evaluation of a novel solubilized formulation of ibuprofen in the treatment of migraine headache: a randomized, double-blind, placebo-controlled, dose-ranging study. Cephalalgia, 20:233-43.

Klapper J. 1997. Divalproex sodium in migraine prophylaxis: a dosecontrolled study. Cephalalgia, 17:103-8.

Kloster R, Nestvold K, Vilming ST. 1992. A double-blind study of ibuprofen versus placebo in the treatment of acute migraine attacks. Cephalalgia, 12:169-71; discussion 128.

Kozubski W, Prusinski A. 1999. [Controlled study of iprazochrome effectiveness (Divascan) in prophylactic treatment of migraine]. Neurol Neurochir Pol, 33:369-76.

Kraus RL, Sinnegger MJ, Glossmann H, et al. 1998. Familial hemiplegic migraine mutations change alpha1 $\mathrm{A} \mathrm{Ca}^{+}$channel kinetics. $J$ Biol Chem, 273:5586-90.

Kraus RL, Sinnegger MJ, Koschak A, et al. 2000. Three new familial hemiplegic migraine mutants affect $\mathrm{P} / \mathrm{Q}$-type $\mathrm{Ca}\left(2^{+}\right)$channel kinetics. J Biol Chem, 275:9239-43.

Krusz J. 2001a. Levetiracetam as prophylaxis for resistant headaches [abstract]. Cephalalgia, 21:373. 
Krusz J. 2001b. Zonisamide in the treatment of headache disorders [abstract]. Cephalalgia, 21:374.

Krusz J, Scott V. 1999. Topiramate in the treatment of chronic migraine and other headaches [abstract]. Headache, 39:363.

Krymchantowski AV, Bigal ME, Moreira PF. 2002. New and emerging prophylactic agents for migraine. CNS Drugs, 16:611-34.

Lampl C, Buzath A, Klinger D, et al. 1999. Lamotrigine in the prophylactic treatment of migraine aura - a pilot study. Cephalalgia, 19:58-63.

Lance JW, Anthony M, Somerville B. 1970. Comparative trial of serotonin antagonists in the management of migraine. $\mathrm{Br}$ Med $J$, 2:327-30.

Lance JW, Fine RD, Curran DA. 1963. An evaluation of methysergide in the prevention of migraine and other vascular headaches. Med J Aust, 50:814-8.

Landy S, McGinnis J, Curlin D, et al. 1999. Selective serotonin reuptake inhibitors for migraine prophylaxis. Headache, 39:28-32.

Lange R, Schwarz JA, Hohn M. 2000. Acetylsalicylic acid effervescent $1000 \mathrm{mg}$ (Aspirin) in acute migraine attacks; a multicentre, randomized, double-blind, single-dose, placebo-controlled parallel group study. Cephalalgia, 20:663-7.

Langohr HD, Gerber WD, Koletzki E, et al. 1985. Clomipramine and metoprolol in migraine prophylaxis - a double-blind crossover study. Headache, 25:107-13.

Langohr HD, Reinecke M, Gerber WD, et al. 1988. [Dihydroergotamine and flunarizine in the prevention of migraine. A comparative double-blind study]. Fortschr Med, 106:65-6, 69-70.

Lanteri-Minet M. 2005. What do patients want from their acute migraine therapy? Eur Neurol, 53 (Suppl 1):3-9.

Lanteri-Minet M, Alchaar H, Besson G, et al. 2000. [Pharmacoepidemiological study on the prophylactic treatment of migraine. National inquiry on attitude to prescription practices by primary care physicians and neurologists in Franceo]. Rev Neurol (Paris), 156:1106-12.

Lanteri-Minet M, Auray JP, El Hasnaoui A, et al. 2003. Prevalence and description of chronic daily headache in the general population in France. Pain, 102:143-9.

Leandri M, Rigardo S, Schizzi R, et al. 1990. Migraine treatment with nicardipine. Cephalalgia, 10:111-6.

Leniger T, Pageler L, Stude P, et al. 2005. Comparison of intravenous valproate with intravenous lysine-acetylsalicylic acid in acute migraine attacks. Headache, 45:42-6.

Lewis DW, Kellstein D, Dahl G, et al. 2002. Children's ibuprofen suspension for the acute treatment of pediatric migraine. Headache, 42:780-6.

Lichten EM, Lichten JB, Whitty A, et al. 1996. The confirmation of a biochemical marker for women's hormonal migraine: the depo-estradiol challenge test. Headache, 36:367-71.

Limmroth V, Katsarava Z, Fritsche G, et al. 2002. Features of medication overuse headache following overuse of different acute headache drugs. Neurology, 59:1011-4.

Linde K, Rossnagel K. 2004. Propranolol for migraine prophylaxis. Cochrane Database Syst Rev, 3:CD003225.

Linton-Dahlof P, Linde M, Dahlof C. 2000. Withdrawal therapy improves chronic daily headache associated with long-term misuse of headache medication:a retrospective study. Cephalalgia, 20:658-62.

Lipton RB, Cutrer FM, Goadsby PJ, et al. 2005a. How treatment priorities influence triptan preferences in clinical practice: perspectives of migraine sufferers, neurologists, and primary care physicians. Curr Med Res Opin, 21:413-24.

Lipton RB, Goldstein J, Baggish JS, et al. 2005b. Aspirin is efficacious for the treatment of acute migraine. Headache, 45:283-92.

Lipton RB, Stewart WF, Cady R, et al. 2000a. 2000 Wolfe Award. Sumatriptan for the range of headaches in migraine sufferers: results of the Spectrum Study. Headache, 40:783-91.

Lipton RB, Stewart WF, Ryan RE Jr., et al. 1998. Efficacy and safety of acetaminophen, aspirin, and caffeine in alleviating migraine headache pain: three double-blind, randomized, placebo-controlled trials. Arch Neurol, 55:210-7.
Lipton RB, Stewart WF, Stone AM, et al. 2000b. Stratified care vs step care strategies for migraine: the Disability in Strategies of Care (DISC) Study: A randomized trial. JAMA, 284:2599-605.

Littleton-Kearney MT, Agnew DM, Traystman RJ, et al. 2000. Effects of estrogen on cerebral blood flow and pial microvasculature in rabbits. Am J Physiol Heart Circ Physiol, 279:H1208-14.

Loder EW, Buse DC, Golub JR. 2005. Headache and combination estrogen-progestin oral contraceptives: integrating evidence, guidelines, and clinical practice. Headache, 45:224-31.

Lofland JH, Nash DB. 2005. Oral serotonin receptor agonists: a review of their cost effectiveness in migraine. Pharmacoeconomics, 23:259-74

Louis P, Schoenen J, Hedman C. 1985. Metoprolol v. clonidine in the prophylactic treatment of migraine. Cephalalgia, 5:159-65.

Lu SR, Fuh JL, Chen WT, et al. 2001. Chronic daily headache in Taipei, Taiwan: prevalence, follow-up and outcome predictors. Cephalalgia, 21:980-6.

Lucas C, Chaffaut C, Artaz MA, et al. 2005. FRAMIG 2000: medical and therapeutic management of migraine in France. Cephalalgia, 25:267-79.

Lucking CH, Oestreich W, Schmidt R, et al. 1988. Flunarizine vs propranolol in the prophylaxis of migraine: two double-blind comparative studies in more than 400 patients. Cephalalgia, (8 Suppl) 8:21-6.

Ludin HP. 1989. Flunarizine and propranolol in the treatment of migraine. Headache, 29:219-24.

Lyngberg AC, Rasmussen BK, Jorgensen T, et al. 2005. Prognosis of migraine and tension-type headache: a population-based follow-up study. Neurology, 65:580-5.

MacGregor EA. 2004. Oestrogen and attacks of migraine with and without aura. Lancet Neurol, 3:354-61.

MacGregor EA, Dowson A, Davies PT. 2002. Mouth-dispersible aspirin in the treatment of migraine: a placebo-controlled study. Headache, 42:249-55.

MacGregor EA, Frith A, Ellis J, et al. 2006. Prevention of menstrual attacks of migraine: a double-blind placebo-controlled crossover study. Neurology, 67:2159-63.

MacGregor EA, Hackshaw A. 2002. Prevention of migraine in the pill-free interval of combined oral contraceptives: a double-blind, placebo-controlled pilot study using natural oestrogen supplements. J Fam Plann Reprod Health Care, 28:27-31.

Maissen CP, Ludin HP. 1991. [Comparison of the effect of 5-hydroxytryptophan and propranolol in the interval treatment of migraine]. Schweiz Med Wochenschr, 121:1585-90.

Martinez HR, Londono O, Cantu-Martinez L, et al. 2003. Topiramate as an adjunctive treatment in migraine prophylaxis. Headache, 43:1080-4.

Martucci N, Manna V, Mattesi P, et al. 1983. Ergot derivatives in the prophylaxis of migraine: a multicentric study with a timed-release dihydroergotamine formulation. Cephalalgia, 3(Suppl 1):151-5.

Massiou H, Serrurier D, Lasserre O, et al. 1991. Effectiveness of oral diclofenac in the acute treatment of common migraine attacks: a double-blind study versus placebo. Cephalalgia, 11:59-63.

Mathew NT. 1993. Transformed migraine. Cephalalgia, 13 Suppl 12:78-83.

Mathew NT. 1997. Transformed migraine, analgesic rebound, and other chronic daily headaches. Neurol Clin, 15:167-86.

Mathew NT, Kailasam J, Meadors L. 2002. Prophylaxis of migraine, transformed migraine, and cluster headache with topiramate. Headache, 42:796-803.

Mathew NT, Kailasam J, Meadors L, et al. 2000. Intravenous valproate sodium (depacon) aborts migraine rapidly: a preliminary report. Headache, 40:720-3.

Mathew NT, Rapoport A, Saper J, et al. 2001. Efficacy of gabapentin in migraine prophylaxis. Headache, 41:119-28.

Mathew NT, Saper JR, Silberstein SD, et al. 1995. Migraine prophylaxis with divalproex. Arch Neurol, 52:281-6.

Mathew NT, Stubits E, Nigam MP. 1982. Transformation of episodic migraine into daily headache: analysis of factors. Headache, 22:66-8. 
McCarthy BG, Peroutka SJ. 1989. Comparative neuropharmacology of dihydroergotamine and sumatriptan (GR 43175). Headache, 29:420-2.

McEwen BS. 2001. Invited review: Estrogens effects on the brain: multiple sites and molecular mechanisms. J Appl Physiol, 91:2785-801.

Mei D, Capuano A, Vollono C, et al. 2004. Topiramate in migraine prophylaxis: a randomised double-blind versus placebo study. Neurol Sci, 25:245-50.

Micieli G, Cavallini A, Marcheselli S, et al. 2001. Alpha-dihydroergocryptine and predictive factors in migraine prophylaxis. Int J Clin Pharmacol Ther, 39:144-51.

[MINES] Migraine-Nimodipine European Study Group. 1989a. European multicenter trial of nimodipine in the prophylaxis of classic migraine (migraine with aura). Headache, 29:639-42.

[MINES] Migraine-Nimodipine European Study Group. 1989b. European multicenter trial of nimodipine in the prophylaxis of common migraine (migraine without aura). Headache, 29:633-8.

Monro P, Swade C, Coppen A. 1985. Mianserin in the prophylaxis of migraine: a double-blind study. Acta Psychiatr Scand Suppl, 320:98-103.

Montastruc JL, Senard JM. 1992. [Calcium channel blockers and prevention of migraine]. Pathol Biol (Paris), 40:381-8.

Mulleners WM, Chronicle EP, Vredeveld JW, et al. 2002. Visual cortex excitability in migraine before and after valproate prophylaxis: a pilot study using TMS. Eur J Neurol, 9:35-40.

Myllyla VV, Havanka H, Herrala L, et al. 1998. Tolfenamic acid rapid release versus sumatriptan in the acute treatment of migraine: comparable effect in a double-blind, randomized, controlled, parallel-group study. Headache, 38:201-7.

Nachit-Ouinekh F, Dartigues JF, Chrysostome V, et al. 2005. Evolution of migraine after a 10-year follow-up. Headache, 45:1280-7.

Nebe J, Heier M, Diener HC. 1995. Low-dose ibuprofen in self-medication of mild to moderate headache: a comparison with acetylsalicylic acid and placebo. Cephalalgia, 15:531-5.

Neuman M, Demarez JP, Harmey JL, et al. 1986. Prevention of migraine attacks through the use of dihydroergotamine. Int J Clin Pharmacol Res, 6:11-3.

Noone JF. 1980. Clomipramine in the prevention of migraine. J Int Med Res, 8(Suppl 3):49-52.

Oldman AD, Smith LA, McQuay HJ, et al. 2002. Pharmacological treatments for acute migraine: quantitative systematic review. Pain, 97:247-57.

Olesen J. 1990. Calcium antagonists in migraine and vertigo. Possible mechanisms of action and review of clinical trials. Eur Neurol, 30(Suppl 2):31-4; discussion 39-41.

Olsson JE, Behring HC, Forssman B, et al. 1984. Metoprolol and propranolol in migraine prophylaxis: a double-blind multicentre study. Acta Neurol Scand, 70:160-8.

Orholm M, Honore PF, Zeeberg I. 1986. A randomized general practice group-comparative study of femoxetine and placebo in the prophylaxis of migraine. Acta Neurol Scand, 74:235-9.

Osterman PO. 1977. A comparison between placebo, pizotifen and 1-isopropyl-3-hydroxy-5-semicarbazono-6-oxo-2.3.5.6tetrahydroindol (Divascan) in migraine prophylaxis. Acta Neurol Scand, 56:17-28.

Ozyalcin SN, Talu GK, Kiziltan E, et al. 2005. The efficacy and safety of venlafaxine in the prophylaxis of migraine. Headache, 45:144-52.

Pascual J, Caminero AB, Mateos V, et al. 2004. Preventing disturbing migraine aura with lamotrigine: an open study. Headache, 44:1024-8.

Pascual J, Leira R, Lainez JM. 2003. Combined therapy for migraine prevention? Clinical experience with a beta-blocker plus sodium valproate in 52 resistant migraine patients. Cephalalgia, 23:961-2.

Pedersen E, Moller CE. 1966. Methysergide in migraine prophylaxis. Clin Pharmacol Ther, 7:520-6.

Peroutka SJ, Lyon JA, Swarbrick J, et al. 2004. Efficacy of diclofenac sodium softgel $100 \mathrm{mg}$ with or without caffeine $100 \mathrm{mg}$ in migraine without aura: a randomized, double-blind, crossover study. Headache, 44:136-41.

Pfaffenrath V. 1993. Efficacy and safety of percutaneous estradiol vs placebo in menstrual migraine. Cephalalgia, 13(Suppl 13):244.
Pradalier A, Dry J, Loisy B, et al. 1988. [Comparative study of indoramin versus dihydroergotamine in the preventive treatment of migraine]. Therapie, 43:293-7.

Pradalier A, Lanteri-Minet M, Geraud G, et al. 2004a. The PROMISE study: PROphylaxis of MIgraine with SEglor (dihydroergotamine mesilate) in French primary care. CNS Drugs, 18:1149-63.

Pradalier A, Vincent D, Beaulieu P. 2004b. Correlation between oestradiol plasma level and therapeutic effect on menstrual migraine. In: Rose $\mathrm{F}$ (Ed.) New Advances in Headache Research. 4th Edition. London, UK: Smith-Gordon.

Rampello L, Alvano A, Chiechio S, et al. 2004. Evaluation of the prophylactic efficacy of amitriptyline and citalopram, alone or in combination, in patients with comorbidity of depression, migraine, and tension-type headache. Neuropsychobiology, 50:322-8.

Rao BS, Das DG, Taraknath VR, et al. 2000. A double blind controlled study of propranolol and cyproheptadine in migraine prophylaxis. Neurol India, 48:223-6.

Reveiz-Herault L, Cardona AF, Ospina EG, et al. 2003. [Effectiveness of flunarizine in the prophylaxis of migraine: a meta-analytical review of the literature]. Rev Neurol, 36:907-12.

Rompel H, Bauermeister PW. 1970. Aetiology of migraine and prevention with carbamazepine (Tegretol): results of a double-blind, cross-over study. S Afr Med J, 44:75-80.

Ryan RE. 1968. Double-blind crossover comparison of bc-105, methysergide and placebo in the prophylaxis of migraine headache. Headache, 8:118-26.

Ryan RE, Sr. 1984. Comparative study of nadolol and propranolol in prophylactic treatment of migraine. Am Heart J, 108:1156-9.

Sandrini G, Franchini S, Lanfranchi S, et al. 1998. Effectiveness of ibuprofen-arginine in the treatment of acute migraine attacks. Int J Clin Pharmacol Res, 18:145-50.

Santucci M, Cortelli P, Rossi PG, et al. 1986. L-5-hydroxytryptophan versus placebo in childhood migraine prophylaxis: a double-blind crossover study. Cephalalgia, 6:155-7.

Saper JR, Silberstein SD, Lake AE, 3rd, et al. 1995. Fluoxetine and migraine: comparison of double-blind trials. Headache, 35:233.

Scher AI, Stewart WF, Liberman J, et al. 1998. Prevalence of frequent headache in a population sample. Headache, 38:497-506.

Scher AI, Stewart WF, Lipton RB. 2004. Caffeine as a risk factor for chronic daily headache: a population-based study. Neurology, 63:2022-7.

Scher AI, Stewart WF, Ricci JA, et al. 2003. Factors associated with the onset and remission of chronic daily headache in a population-based study. Pain, 106:81-9.

Schuaib A, Ahmed F, Muratoglu M, et al. 1999. Topiramate in migraine prophylaxis: a pilot study [abstract]. Cephalalgia, 19:379-80.

Sculpher M, Millson D, Meddis D, et al. 2002. Cost-effectiveness analysis of stratified versus stepped care strategies for acute treatment of migraine: The Disability in Strategies for Care (DISC) Study. Pharmacoeconomics, 20:91-100.

Shekelle RB, Ostfeld AM. 1964. Methysergide in the Migraine Syndrome. Clin Pharmacol Ther, 5:201-4.

Shukla R, Garg RK, Nag D, et al. 1995. Nifedipine in migraine and tension headache: a randomised double blind crossover study. J Assoc Physicians India, 43:770-2.

Silberstein S, Merriam G. 1999. Sex hormones and headache 1999 (menstrual migraine). Neurology, 53:S3-13.

Silberstein SD. 1998. Methysergide. Cephalalgia, 18:421-35.

Silberstein SD. 2000. Practice parameter: evidence-based guidelines for migraine headache (an evidence-based review): report of the Quality Standards Subcommittee of the American Academy of Neurology. Neurology, 55:754-62.

Silberstein SD, Goadsby PJ. 2002. Migraine: preventive treatment. Cephalalgia, 22:491-512.

Silberstein SD, Neto W, Schmitt J, et al. 2004. Topiramate in migraine prevention: results of a large controlled trial. Arch Neurol, 61:490-5.

Silberstein SD, Winner PK, Chmiel JJ. 2003. Migraine preventive medication reduces resource utilization. Headache, 43:171-8. 
Silvestrini M, Bartolini M, Coccia M, et al. 2003. Topiramate in the treatment of chronic migraine. Cephalalgia, 23:820-4.

Siniatchkin M, Gerber WD, Vein A. 1998. Clinical efficacy and central mechanisms of cyclandelate in migraine: a double-blind placebo-controlled study. Funct Neurol, 13:47-56.

Snow V, Weiss K, Wall EM, et al. 2002. Pharmacologic management of acute attacks of migraine and prevention of migraine headache. Ann Intern Med, 137:840-9.

Solomon GD. 1989. Verapamil in migraine prophylaxis - a five-year review. Headache, 29:425-7.

Solomon S, Lipton RB, Newman LC. 1992. Clinical features of chronic daily headache. Headache, 32:325-9.

Somerville BW. 1972. The role of estradiol withdrawal in the etiology of menstrual migraine. Neurology, 22:355-65.

Somerville BW. 1975. Estrogen-withdrawal migraine. I. Duration of exposure required and attempted prophylaxis by premenstrual estrogen administration. Neurology, 25:239-44.

Somerville BW, Carey HM. 1970. The use of continuous progestogen contraception in the treatment of migraine. Med J Aust, 1:1043-5.

Somerville BW, Herrmann WM. 1978. Migraine prophylaxis with Lisuride hydrogen maleate--a double blind study of Lisuride versus placebo. Headache, 18:75-9.

Sorensen PS, Larsen BH, Rasmussen MJ, et al. 1991. Flunarizine versus metoprolol in migraine prophylaxis: a double-blind, randomized parallel group study of efficacy and tolerability. Headache, 31:650-7.

Steardo L, Bonuso S, Di Stasio E, et al. 1982. Selective and non-selective beta-blockers: are both effective in prophylaxis of migraine? A clinical trial versus methysergide. Acta Neurol (Napoli), 4:196-204.

Steardo L, Marano E, Barone P, et al. 1986. Prophylaxis of migraine attacks with a calcium-channel blocker: flunarizine versus methysergide. J Clin Pharmacol, 26:524-8.

Steiner TJ, Ahmed F, Findley LJ, et al. 1998. S-fluoxetine in the prophylaxis of migraine: a phase II double-blind randomized placebo-controlled study. Cephalalgia, 18:283-6

Steiner TJ, Findley LJ, Yuen AW. 1997. Lamotrigine versus placebo in the prophylaxis of migraine with and without aura. Cephalalgia, 17:109-12.

Steiner TJ, Joseph R, Hedman C, et al. 1988. Metoprolol in the prophylaxis of migraine: parallel-groups comparison with placebo and dose-ranging follow-up. Headache, 28:15-23.

Stellar S, Ahrens SP, Meibohm AR, et al. 1984. Migraine prevention with timolol. A double-blind crossover study. JAMA, 252:2576-80.

Stensrud P, Sjaastad O. 1979. Clonazepam (rivotril) in migraine prophylaxis. Headache, 19:333-4.

Stensrud P, Sjaastad O. 1980. Comparative trial of Tenormin (atenolol) and Inderal (propranolol) in migraine. Headache, 20:204-7.

Storey JR, Calder CS, Hart DE, et al. 2001. Topiramate in migraine prevention: a double-blind, placebo-controlled study. Headache, 41:968-75.

Stronks DL, Tulen JH, Bussmann HB, et al. 2003. Effects of naratriptan versus naproxen on daily functioning in the acute treatment of migraine: a randomized, double-blind, double-dummy, crossover study. Headache, 43:845-52.

Sudilovsky A, Elkind AH, Ryan RE Sr., et al. 1987. Comparative efficacy of nadolol and propranolol in the management of migraine. Headache, 27:421-6.

Tanen DA, Miller S, French T, et al. 2003. Intravenous sodium valproate versus prochlorperazine for the emergency department treatment of acute migraine headaches: a prospective, randomized, double-blind trial. Ann Emerg Med, 41:847-53.
Tfelt-Hansen P, Block G, Dahlof C, et al. 2000. Guidelines for controlled trials of drugs in migraine: second edition. Cephalalgia, 20:765-86

Tfelt-Hansen P, Henry P, Mulder LJ, et al. 1995. The effectiveness of combined oral lysine acetylsalicylate and metoclopramide compared with oral sumatriptan for migraine. Lancet, 346:923-6.

Tfelt-Hansen P, Olesen J. 1984. Effervescent metoclopramide and aspirin (Migravess) versus effervescent aspirin or placebo for migraine attacks: a double-blind study. Cephalalgia, 4:107-11.

The Diclofenac-K/Sumatriptan Migraine Study Group. 1999. Acute treatment of migraine attacks: efficacy and safety of a nonsteroidal anti-inflammatory drug, diclofenac-potassium, in comparison to oral sumatriptan and placebo. Cephalalgia, 19:232-40.

[TOSAM] The Oral Sumatriptan and Aspirin plus Metoclopramide Comparative Study Group. 1992. A study to compare oral sumatriptan with oral aspirin plus oral metoclopramide in the acute treatment of migraine. Eur Neurol, 32:177-84.

Titus F, Davalos A, Alom J, et al. 1986. 5-Hydroxytryptophan versus methysergide in the prophylaxis of migraine. Randomized clinical trial. Eur Neurol, 25:327-9.

Tomkins GE, Jackson JL, O'Malley PG, et al. 2001. Treatment of chronic headache with antidepressants: a meta-analysis. Am J Med, 111:54-63.

Tomson T, Battino D. 2005. Teratogenicity of antiepileptic drugs: state of the art. Curr Opin Neurol, 18:135-40.

Ulrich V, Gervil M, Fenger K, et al. 1999. The prevalence and characteristics of migraine in twins from the general population. Headache, 39:173-80.

Vilming S, Standnes B, Hedman C. 1985. Metoprolol and pizotifen in the prophylactic treatment of classical and common migraine. A doubleblind investigation. Cephalalgia, 5:17-23.

Von Seggern RL, Mannix LK, Adelman JU. 2002. Efficacy of topiramate in migraine prophylaxis: a retrospective chart analysis. Headache, 42:804-9.

Wang SJ, Fuh JL, Lu SR, et al. 2000. Chronic daily headache in Chinese elderly: prevalence, risk factors, and biannual follow-up. Neurology, 54:314-9.

Wasserfallen JM. 1976. [Double-blind study with oxetorone in cephalalgia (author's trans1)]. Schweiz Rundsch Med Prax, 65:1021-4.

Weber RB, Reinmuth OM. 1972. The treatment of migraine with propranolol. Neurology, 22:366-9.

Welch KM. 2003. Contemporary concepts of migraine pathogenesis. Neurology, 61:S2-8.

Wide K, Winbladh B, Kallen B. 2004. Major malformations in infants exposed to antiepileptic drugs in utero, with emphasis on carbamazepine and valproic acid: a nation-wide, population-based register study. Acta Paediatr, 93:174-6.

Young WB, Hopkins MM, Shechter AL, et al. 2002. Topiramate: a case series study in migraine prophylaxis. Cephalalgia, 22:659-63.

Young WB, Siow HC, Silberstein SD. 2004. Anticonvulsants in migraine. Curr Pain Headache Rep, 8:244-50.

Zeeberg I, Orholm M, Nielsen JD, et al. 1981. Femoxetine in the prophylaxis of migraine - a randomised comparison with placebo. Acta Neurol Scand, 64:452-9.

Zivadinov R, Willheim K, Sepic-Grahovac D, et al. 2003. Migraine and tension-type headache in Croatia: a population-based survey of precipitating factors. Cephalalgia, 23:336-43.

Zwart JA, Dyb G, Hagen K, et al. 2003. Analgesic use: a predictor of chronic pain and medication overuse headache: the Head-HUNT Study. Neurology, 61:160-4. 